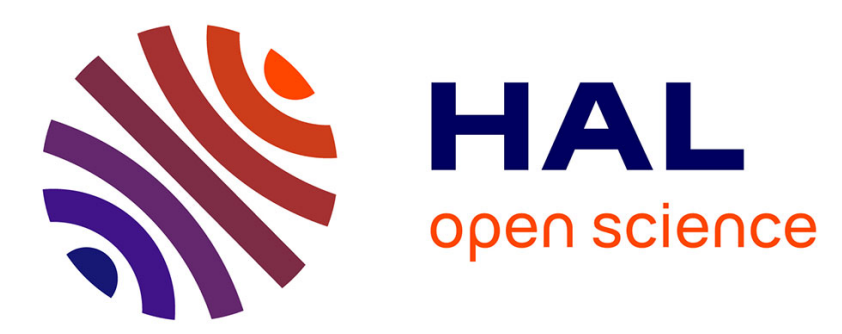

\title{
Energy transfers between multidecadal and turbulent variability
}

Antoine Hochet, Thierry Huck, Olivier Arzel, Florian Sévellec, Alain Colin de Verdière

\section{- To cite this version:}

Antoine Hochet, Thierry Huck, Olivier Arzel, Florian Sévellec, Alain Colin de Verdière. Energy transfers between multidecadal and turbulent variability. Journal of Climate, In press, 35 (4), pp.11571178. 10.1175/JCLI-D-21-0136.1 . hal-03390256

\section{HAL Id: hal-03390256 https://hal.science/hal-03390256}

Submitted on 21 Oct 2021

HAL is a multi-disciplinary open access archive for the deposit and dissemination of scientific research documents, whether they are published or not. The documents may come from teaching and research institutions in France or abroad, or from public or private research centers.
L'archive ouverte pluridisciplinaire HAL, est destinée au dépôt et à la diffusion de documents scientifiques de niveau recherche, publiés ou non, émanant des établissements d'enseignement et de recherche français ou étrangers, des laboratoires publics ou privés. 


\section{Energy transfers between multidecadal and turbulent variability}

2. Antoine Hochet* , Thierry Huck, Olivier Arzel, Florian Sévellec, and Alain Colin de Verdière

Univ Brest, CNRS, Ifremer, IRD, Laboratoire d'Océanographie Physique et Spatiale (LOPS, UMR 6523), IUEM, Brest, France

${ }_{5}^{*}$ Corresponding author address: Antoine Hochet, Univ of Brest, CNRS, Ifremer, IRD, Laboratoire 6 d'Océanographie Physique et Spatiale (LOPS, UMR 6523), IUEM, Brest, France

7 E-mail: antoine.hochet@univ-brest.fr 


\section{ABSTRACT}

${ }_{27}$ a minor influence on the multidecadal mode compared to the other energy

One of the proposed mechanisms to explain the multidecadal variability observed in sea surface temperature of the North Atlantic consists of a largescale low-frequency internal mode spontaneously developing because of the large-scale baroclinic instability of the time-mean circulation. Even though this mode has been extensively studied in terms of the buoyancy variance budget, its energetic properties remain poorly known. Here we perform the full mechanical energy budget including available potential energy (APE) and kinetic energy (KE) of this internal mode and decompose the budget into three frequency bands: mean, low frequency (LF) associated with the large-scale mode and high frequency (HF) associated with mesocale eddy turbulence. This decomposition allows us to diagnose the energy fluxes between the different reservoirs and to understand the sources and sinks. Due to the largescale of the mode, most of its energy is contained in the APE. In our configuration, the only source of LF APE is the transfer from mean APE to LF APE that is attributed to the large-scale baroclinic instability. In return the sinks of LF APE are the parameterized diffusion, the flux toward HF APE and to a much lesser extent toward LF KE. The presence of an additional wind-stress component weakens multidecadal oscillations and modifies the energy fluxes between the different energy reservoirs. The KE transfer appears to only have sources involving APE, in all experiments. These results highlight the utility of the full APE/ KE budget. 


\section{Introduction}

The multidecadal large-scale variability of the Sea Surface Temperature (SST) is characterised in the North Atlantic by an anomaly intensified in the subpolar region and by a weaker anomaly of opposite sign south of the equator (Kushnir 1994; Deser et al. 2010; Zhang et al. 2019). This large scale SST variability has been named Atlantic Multidecadal Variability (AMV, Kushnir 1994; Schlesinger and Ramankutty 1994; Kerr 2000; Sutton et al. 2018). Cool AMV phases occurred in the 1900s-1920s, 1960s-1990s and warm phases occurred in the 1930s-1960s and after 1995. These cool and warm phases have been shown to be associated with several regional climate impacts such as the Sahel Indian summer monsoon rainfall, Atlantic hurricanes frequency, summer climate over western Europe and north America (Zhang et al. 2019), wave climate in the Atlantic and Pacific Ocean (Reguero et al. 2019). Observations moreover show that more heat is released from the North Atlantic ocean to the atmosphere during a positive phase of the AMV (Gulev et al. 2013). Thus understanding what controls the dynamics of this variability and its potential predictability have essential societal and economics implications (Sutton et al. 2018).

Several mechanisms have been proposed to explain the origin of the AMV and remain actively debated (see for instance the recent discussion in Clement et al. 2015; Zhang et al. 2016; Clement et al. 2016). Some studies suggest a direct role of the atmosphere either via stochastic heat flux (Hasselmann 1976; Frankignoul and Hasselmann 1977; Clement et al. 2015) or via aerosol emissions (Booth et al. 2012), while other studies (e.g. Sévellec and Fedorov 2013; Arzel et al. 2018) suggest a role for oceanic processes linked with the internal variability of the Atlantic Meridional Overturning Circulation (AMOC). In this work we focus on improving our knowledge of the physics of internal ocean modes which are one of the possible explanations for the AMV. At low resolution, internal interdecadal variability arises in rectangular flat bottomed single hemispheric 
basin forced by prescribed surface heat fluxes (Greatbatch and Zhang 1995; Huck et al. 1999). This internal variability is due to a large-scale baroclinic instability that gives rise to SST anomalies and to geostrophically-induced Meridional Overturning Circulation variability (Colin de Verdière and Huck 1999; Te Raa and Dijkstra 2002). This mode of variability and its mechanism were also demonstrated to exist in global realistic configuration of an Ocean General Circulation Model (OGCM) (Sévellec and Fedorov 2013), in idealized coupled models (Buckley et al. 2012; Jamet et al. 2016), in climate models (Muir and Fedorov 2017) and in observations (Frankcombe et al. 2008). It is also shown to produce maximum SST variance in the region where the AMV signature is observed (Arzel et al. 2018).

The mode can be damped in some models (such as in the study of Sévellec and Fedorov (2013)) and self-sustained in others (Huck et al. (2015) for instance). The damped or self-sustained nature of the mode depends on different parameters such as the topography (Winton 1997), the wind shape and strength, or the vertical and horizontal diffusion (Huck et al. 2001; Arzel et al. 2018). In the case of a damped mode, atmospheric stochastic forcing is needed to excite the mode. Frankcombe et al. (2009) showed that the introduction of a North Atlantic Oscillation type stochastic forcing leads to an amplitude of sea surface temperature variability comparable to observations. Arzel et al. (2018) studied the bifurcation structure of the mode in a realistic configuration forced by prescribed surface fluxes and showed that the mode becomes damped for eddy induced diffusivities larger than $600 \mathrm{~m} \mathrm{~s}^{-1}$.

In addition to available potential energy fluxes associated with the large-scale instability mechanism, ocean mesoscales eddies have been shown to be at the origin of a spatio-temporal inverse cascade of kinetic energy (Arbic et al. 2014; Martin et al. 2020). This latter mechanism has been proposed to be central to the existence of interannual-to-decadal fluctuations of sea level anomalies and surface kinetic energy in global-scale eddying simulations (Penduff et al. 2011; Arbic 
et al. 2014; Sérazin et al. 2015, 2018; Martin et al. 2020) and to influence the AMOC variability (Grégorio et al. 2015; Leroux et al. 2018; Jamet et al. 2019). However, realistic and globalscale eddy resolving simulations of multidecadal variability are still beyond reach because of the long-time integration required to bring the circulation in near equilibrium with the weak interior diffusive vertical fluxes. Therefore most of the studies devoted to this problem are based on simple box-model geometries (e.g., Spall 2008; Huck et al. 2015; Hochet et al. 2020). How the oceanic mesoscale turbulence influences the multidecadal mode that spontaneously develops under prescribed surface fluxes has been explored by Huck et al. (2015). These authors show that, in the presence of mesoscale turbulence, the primary mechanism driving multidecadal-scale temperature fluctuations remains the large-scale baroclinic instability mechanism. The presence of a surface restoring boundary condition in Spall (2008) prevents the internal ocean mode from developing so that the wind-driven gyre circulation and subsequent mesoscale instabilities play a major role. The coexistence of the mode described above and mesoscale eddies was shown by Huck et al. (2015) using idealized simulations at eddy-resolving resolution. In such eddying configurations and using a frequency-domain approach, Hochet et al. (2020) have highlighted a non-linear transfer of temperature variance from low to high frequencies: mesoscale eddies are a sink of temperature variance for the low frequency mode. Hence low-frequencies do not arise as the result of the mesoscale eddy field, as in Spall (2008) for instance, but instead draw their energy source from the large-scale stratification. Sévellec et al. (2020) have also shown a similar behavior using mooring data in the Southern Ocean, but on shorter timescale. However the use of temperature variance instead of an energetic framework, as in Arbic et al. (2014) or Sérazin et al. $(2015,2018)$ makes the comparison with results from these studies difficult. Temperature variance is up to a factor equal to the local definition of available potential energy (APE) $\varepsilon_{A P E}$ in a Quasi-Geostrophic (QG) 
framework:

$$
\varepsilon_{A P E} \approx \frac{1}{2} \frac{g^{2} \rho^{\prime 2}}{\rho_{0} N^{2}}
$$

with $N$ the Brunt-Väisälä frequency, $g$ the acceleration of gravity parameter, $\rho^{\prime}$ the density anomaly and $\rho_{0}$ the reference density. However, the internal mode described in the literature cited above occurs in regions where isopycnals outcropping prevents the use of (1). Thus diagnostics and budget of temperature variance do not permit identifying the sources and sinks of energy. In this article we seek to obtain the full energy budget (i.e., including both kinetic energy (KE) and available potential energy) for the low frequency mode described for instance in Hochet et al. (2020) and to quantify the energy transfers associated with the time mean flow and mesoscale eddy field. In particular we want to compare the intensity and direction of the conversion between Low Frequency (LF) and High Frequency (HF) KE and between LF and HF APE. Because the only source of KE in the buoyancy forced experiment of Hochet et al. (2020) is the APE/KE conversion terms, we also investigate the effect of a wind stress forcing to add a direct source of KE.

The main difficulty in obtaining the energy budget in different frequency bands lies in the APE decomposition. Indeed, contrary to the kinetic energy, the time decomposition of the full APE formula is not straightforward. Scotti and White (2014) circumvented this problem by computing the fluctuating APE as the difference between the APE for the total circulation (i.e., time mean and fluctuations) and the APE for the time mean circulation. This idea has been applied by Zemskova et al. (2015) to an eddy permitting ocean state estimate (from the "Estimating the Circulation and Climate of the Ocean", Phase II) to decompose the APE and KE budget into time mean and fluctuating components. More recently, the same method has been used by Zemskova et al. (2021) to study the influence of several wind intensities over the Southern Ocean on the time mean and fluctuating components of the APE and KE budget. They found that the APE budget is not significantly affected by the surface wind stress and mainly controlled by the surface buoyancy forcing. 
However we will show that applying this method to our configuration leads to a spurious imprint of the time-independent surface heat flux forcing on the LF and HF APE reservoirs, whereas we would instead expect the energy flux associated with the steady forcing to be entirely imparted to the background stratification. We will thus develop an alternative method that will be used to decompose the APE into mean, low frequency, and high frequency parts.

The article is organised as follows: in section 2, we decompose the mean, low- and highfrequencies and derive the budget for APE and KE. In section 3, we give a description of the model configuration used in this study. In section 4 , we describe the variability in three numerical simulations with idealized North Atlantic configuration and under prescribed surface heat flux forcing with different wind forcing intensities. In Section 5, we apply the energy budgets described in section 2 on the simulation outputs. In section 6 , we conclude and discuss the main findings.

\section{Theory}

In this section we derive the APE and KE budgets for the mean, LF and HF circulations. We use a linear equation of state for the density $\rho$ that is only a function of temperature: $\rho=\rho_{0}(1-\alpha \theta)$ where $\theta$ is the temperature, $\alpha=2 \times 10^{-4} \mathrm{~K}^{-1}$ the uniform thermal expansion coefficient and $\rho_{0}=1027.5 \mathrm{~kg} \mathrm{~m}^{-3}$ the reference density (consistently with the ocean model used, see section 3 for the full model description). The equation for $\rho$ is then:

$$
\frac{\partial \rho}{\partial t}+\mathbf{v} \cdot \nabla \rho=\mathrm{D}+\mathrm{F}
$$

where $\mathbf{v}=(u, v, w)$ is the $3 \mathrm{~d}$ velocity with $u, v, w$ the zonal, meridional, and vertical velocities. $\mathrm{D}$ and $\mathrm{F}$ represent the dissipation and surface forcing of density, respectively, the latter being constant with time and zero below the surface (i.e. no penetrative radiation). The time independent forcing is used here to keep the problem simple, we therefore do not account for slow variation 
157

of the forcing linked for instance with climate change. Note that the generalization of the theory presented below to a time dependent $F$ and to penetrative radiation is straightforward.

To obtain a separate budget for the low and high frequency parts of the APE and KE we decompose each field $M$ into mean, low and high frequency parts:

$$
M=\bar{M}+M^{\mathrm{LF}}+M^{\mathrm{HF}},
$$

where $M^{\mathrm{LF}}$ and $M^{\mathrm{HF}}$ are the low and high frequency parts of $M$, respectively, and $\bar{M}$ the time mean. The time mean is computed using the following formula:

$$
\bar{M}=\frac{1}{T} \int_{T} M \mathrm{~d} t
$$

where $T$ is the time length over which the integral is computed so that: $M^{\mathrm{LF}}$ and $M^{\mathrm{HF}}$ satisfy $\overline{M^{\mathrm{HF}}}=\overline{M^{\mathrm{LF}}}=\overline{M^{\mathrm{LF}} M^{\mathrm{HF}}}=0$. To decompose into HF and LF we use a low pass Butterworth filter (cut-off frequency given in the following section). The low-pass filter is represented by . so that $M^{\mathrm{HF}}$ satisfies $\widetilde{M^{H F}}=0$ and $\widetilde{M}=\bar{M}+M^{\mathrm{LF}}$.

Using this decomposition in frequency bands on Eq. (2) gives the following evolution equations for the mean, LF and HF of $\rho$ :

$$
\frac{\partial \bar{\rho}}{\partial t}=-\overline{\mathbf{v}} \cdot \nabla \bar{\rho}-\overline{\mathbf{v}^{L F} \cdot \nabla \rho^{L F}}-\overline{\mathbf{v}^{H F} \cdot \nabla \rho^{H F}}+\bar{D}+F
$$

$$
\frac{\partial \rho^{L F}}{\partial t}=-\overline{\mathbf{v}} \cdot \nabla \rho^{L F}-\mathbf{v}^{L F} \cdot \nabla\left(\bar{\rho}+\rho^{L F}\right)+\overline{\mathbf{v}^{H F} \cdot \nabla \rho^{H F}}-\mathbf{v}^{H F \cdot \nabla \rho^{H F}}+\overline{\mathbf{v}^{L F} \cdot \nabla \rho^{L F}}+D^{L F}
$$

$$
\frac{\partial \rho^{H F}}{\partial t}=-\overline{\mathbf{v}} \cdot \nabla \rho^{H F}-\mathbf{v}^{L F} \cdot \nabla \rho^{H F}-\mathbf{v}^{H F} \cdot \nabla\left(\bar{\rho}+\rho^{L F}+\rho^{H F}\right)+\mathbf{v}^{H F \cdot \nabla \rho^{H F}}+D^{H F}
$$

APE is obtained as the difference between Potential Energy (PE) and Background Potential Energy (BPE). We derive expressions for PE, BPE, and APE in sections $\mathrm{a}, \mathrm{b}$ and $\mathrm{c}$ below. 


\section{a. Potential Energy}

Multiplying Eq. (5) by $z g$ gives an equation for the mean PE :

$\frac{\partial g z \bar{\rho}}{\partial t}=-\nabla \cdot(g \overline{\mathbf{v}} z \bar{\rho})+g \bar{w} \bar{\rho}+g \overline{w^{H F} \rho^{H F}}+g \overline{w^{L F} \rho^{L F}}-\nabla \cdot\left(g z\left(\overline{\mathbf{v}^{\mathbf{H F}} \rho^{H F}}+\overline{\mathbf{v}^{\mathbf{L F}} \rho^{L F}}\right)\right)+g z \bar{D}+g z \bar{F}$,

Integrating Eq. (8) on the volume $V$ of the basin and time averaging results in the following equation:

$$
\frac{d P E^{M E A N}}{d t}=\underbrace{\int_{V} g \bar{w} \bar{\rho} \mathrm{d} V}_{-C\left(P E^{M E A N}, K E^{M E A N}\right)}+\underbrace{\int_{V} g \overline{w^{L F} \rho^{L F}} \mathrm{~d} V}_{-C\left(P E^{M E A N}, P E^{L F}\right)}+\underbrace{\int_{V} g \overline{w^{H F} \rho^{H F}} \mathrm{~d} V}_{-C\left(P E^{M E A N}, P E^{H F}\right)}+\underbrace{\int_{V} g z \bar{D} \mathrm{~d} V}_{D_{P E}},
$$

Note that the volume integral of the forcing term multiplied by $z$ disappears because $z=0$ at the surface and $\bar{F}$ is zero below the surface. We note $C(A, B)$ the conversion term from $A$ to $B$ with $C(A, B)=-C(B, A)$, if $C(A, B)>0$ then $C(A, B)$ acts to increase $B$ i. $C\left(P E^{M E A N}, K E^{M E A N}\right)$, $C\left(P E^{M E A N}, P E^{L F}\right)$ and $C\left(P E^{M E A N}, P E^{H F}\right)$ are respectively the conversion of mean $P E$ to mean $K E$, of mean $P E$ to LF $P E$ and of mean $P E$ to HF $P E$. $D_{P E}$ is interpreted as the rate of conversion of internal energy to potential energy (e.g. Hughes et al. 2009). There is no potential energy in anomalies because $\overline{g z \rho^{L F}}=\overline{g z \rho^{H F}}=0$, therefore $P E^{L F}=P E^{H F}=0$. However, following Zemskova et al. (2015), we attribute the two terms $\int_{V} g \overline{w^{H F} \rho^{H F}} \mathrm{~d} V$ and $\int_{V} g \overline{w^{L F} \rho^{L F}} \mathrm{~d} V$ to $C\left(P E^{M E A N}, P E^{H F}\right)$ and $C\left(P E^{M E A N}, P E^{L F}\right)$ so that the formal budgets for $P E^{L F}$ and $P E^{H F}$ are:

$$
\frac{d P E^{L F}}{d t}=-C\left(P E^{L F}, K E^{L F}\right)+C\left(P E^{M E A N}, P E^{L F}\right)
$$

and:

$$
\frac{d P E^{H F}}{d t}=-C\left(P E^{H F}, K E^{H F}\right)+C\left(P E^{M E A N}, P E^{H F}\right)
$$

From which we deduce that: $C\left(P E^{H F}, K E^{H F}\right)=C\left(P E^{M E A N}, P E^{H F}\right)$ and $C\left(P E^{L F}, K E^{L F}\right)=$ $C\left(P E^{M E A N}, P E^{L F}\right)$ 


\section{b. Background Potential Energy}

To obtain an equation for the BPE, we first define the reference level $z_{r}(\rho, t)$ which is a function of time and density and corresponds to the depth that $\rho$ would have in the Lorenz state of minimum potential energy (Lorenz 1955), a state where isopycnal surfaces would be horizontal. Following Saenz et al. (2015), a simple relationship between $\rho$ and its reference level $z_{r}$ can be derived using the result that an adiabatic rearrangement of the fluid parcels conserves the volume:

$$
\int_{V(\rho, t)} \mathrm{d} V=\int_{z_{r}}^{0} A\left(z_{r}\right) \mathrm{d} z_{r},
$$

where $V(\rho, t)$ is the volume of water parcels with density $\rho^{\prime}$ lower than $\rho$ at time $t, A(z)$ is the area of the ocean at depth $z$. With a non-linear equation of state for density that depends on temperature, salinity and pressure, the procedure to obtain $z_{r}$ is quite complex and described for instance in Saenz et al. (2015). However, in this work we use two assumptions that greatly simplify the calculation of $z_{r}$. The first is the assumption of a linear equation of state depending only on temperature. This implies that $z_{r}$ is a function of density $\rho$ (which is itself a function of temperature: $\left.\rho=\rho_{0}(1-\alpha \theta)\right)$ and time $t: z_{r}=Z_{r}(\rho, t)$. The second assumption is the flat bottom basin with vertical boundaries so that the basin area is independant of depth, i.e. $A(z)=A$. Using Eq. (12), $z_{r}$ is then simply:

$$
z_{r}(\rho, t)=-\frac{V(\rho, t)}{A},
$$

Note that with a depth dependent ocean area, the reference depth can easily be obtained by solving Eq. (12). A schematic illustrating how the reference depth $z_{r}(\rho, t)$ is obtained using volume $V(\rho)$ is shown in Figure 1. This reference depth can be used to rewrite the density $\rho$ as a function of $z_{r}$ such that: $\rho(X, t)=\rho_{r}\left(Z_{r}(X, t), t\right)$, with $Z_{r}(X, t)=z_{r}(\rho(X, t), t)$. On this schematic and in this article, we call "physical space" the usual space described by $X=(x, y, z)$ and $t$, and the "reference space" the space described by the reference depth $z_{r}$ and $t$. 
Figure 2 shows the reference depth $z_{r}$ as a function of time for different values of temperature from a simulation that will be presented in a following section. The time variation of the function $z_{r}(\rho, t)$ cannot be neglected here because it varies by more than $500 \mathrm{~m}$ for the largest densities due to the presence of the large-scale, low-frequency, mode. In Zemskova et al. (2015) $z_{r}$ variations with time are small because their study is not focused on the same timescale as ours: their time mean is computed over 20 years and their temporal variability is made of inter-annual, seasonal and shorter timescales while our focus is on decadal to multi-decadal timescales. Note that the larger variations of reference depth at larger densities can be attributed to the stronger (weaker) $\rho_{r}$ gradient at shallower (deeper) reference depth. Time variation of the reference depths due to seasonal variation and to the presence of eddies was also reported in Zemskova et al. (2015).

The background potential energy is defined as follows:

$$
B P E=\int_{V} g Z_{r}(X, t) \rho(X, t) \mathrm{d} V=\int_{-H}^{0} A g z_{r}^{\prime} \rho_{r}\left(z_{r}^{\prime}, t\right) d z_{r}^{\prime},
$$

where $H$ is the basin depth (so that $A H=V$ ) and where the last equality is obtained from equation (12) and describes the calculation of the BPE in the reference space. We now want to obtain separate budgets for the mean, LF, and HF BPE. In Zemskova et al. (2015) the BPE budget is computed by first calculating the BPE of the mean flow that they define as:

$$
B P E_{\mathrm{Z}}^{\mathrm{MEAN}}=\int_{V} g \bar{\rho} z_{r}(\bar{\rho}) \mathrm{d} V
$$

where $z_{r}$ is the reference depth associated with $\bar{\rho}$. The BPE of anomalies is then defined as the difference between the total BPE and the mean BPE:

$$
B P E_{Z}^{\text {anomalies }}=\int_{V}\left(g \overline{\rho z_{r}(\rho, t)}-g \bar{\rho} z_{r}(\bar{\rho})\right) \mathrm{d} V,
$$


Using this method in our simulation leads to part of the time independent heat flux forcing being attributed to $B P E_{Z}^{\text {anomalies }}$. Indeed, in this framework, the BPE forcing by heat fluxes is:

$$
\int_{V} g \bar{F}\left(\overline{z_{r}(\rho, t)}-z_{r}(\bar{\rho})\right) \mathrm{d} V
$$

where $\bar{F}$ is the time-independent net heat flux at the surface. Because of the non-linearity of the $z_{r}$ function (and its time dependence) we have that:

$$
\frac{z_{r}\left(\rho_{1}\right)+z_{r}\left(\rho_{2}\right)}{2} \neq z_{r}\left(\frac{\rho_{1}+\rho_{2}}{2}\right)
$$

for two different densities $\rho_{1} \neq \rho_{2}$. Thus the term in Eq. (17) is non-zero and the time independent forcing acts on the anomalies. However an analysis in terms of density variance shows that the time independent heat flux only acts on time mean density (Hochet et al. 2020). Density anomalies are found to be forced only by the term $\overline{\rho^{\prime} \mathbf{u}^{\prime}} \cdot \nabla \bar{\rho}$ which is usually interpreted as the signature of a large-scale baroclinic instability (see Colin de Verdière and Huck 1999). The fact that the term in Eq. (17) is non-zero is thus at odds with this interpretation.

To circumvent this problem we develop below an alternative method to separate the BPE in frequency bands. The readers not interested in the details of the BPE decomposition may skip this section and refer to figure 3 which gives an intuitive view of the transfer between the different reservoirs.

As in the previous section, $\rho$ is first decomposed into three frequency bands: mean, lowfrequency, and high frequency so that:

$$
\rho=\bar{\rho}+\rho^{L F}+\rho^{H F},
$$

$\rho(X, t)=\rho_{r}\left(z_{r}, t\right)$ can trivially be written as:

$$
\rho\left(z_{r}, t\right)=-\frac{1}{A} \frac{\partial}{\partial z_{r}} \int_{V\left(z_{r}\right)} \rho(X, t) \mathrm{d} V
$$


where $V\left(z_{r}\right)$ is the volume of water with $z_{r}^{\prime}>z_{r}$. This formula simply states that the average of $\rho$ on $z_{r}$ surfaces is $\rho$ by definition of $z_{r}(\rho, t)$. Using Eq. (19) in Eq. (20) gives:

$$
\rho=-\underbrace{\frac{1}{A} \frac{\partial}{\partial z_{r}} \int_{V\left(z_{r}\right)} \bar{\rho} \mathrm{d} V}_{\rho_{r}^{M E A N}\left(z_{r}, t\right)} \underbrace{-\frac{1}{A} \frac{\partial}{\partial z_{r}} \int_{V\left(z_{r}\right)} \rho^{L F} \mathrm{~d} V}_{\rho_{r}^{L F}\left(z_{r}, t\right)} \underbrace{-\frac{1}{A} \frac{\partial}{\partial z_{r}} \int_{V\left(z_{r}\right)} \rho^{H F} \mathrm{~d} V}_{\rho_{r}^{H F}\left(z_{r}, t\right)}
$$

where $\rho_{r}^{M E A N}, \rho_{r}^{L F}$, and $\rho_{r}^{H F}$ are the average of $\rho^{M E A N}, \rho^{L F}$ and $\rho^{H F}$, respectively, on $z_{r}$ surfaces. This ensures that $\rho_{r}^{M E A N}, \rho_{r}^{L F}$ and $\rho_{r}^{H F}$ are functions of $z_{r}$ (and time) and this property will be useful to obtain an evolution equation for the BPE as will become clear below. The BPE is then decomposed as follows:

$$
\begin{aligned}
B P E= & \int_{V} \overline{\rho g z_{r}(\rho, t)} \mathrm{d} V= \\
& \underbrace{\int_{V} \overline{\rho_{r}^{M E A N}\left(z_{r}, t\right) g z_{r}(\rho, t)} \mathrm{d} V}_{B P E^{M E A N}}+\underbrace{\int_{V} \overline{\rho_{r}^{L F}\left(z_{r}, t\right) g z_{r}(\rho, t)} \mathrm{d} V}_{B P E^{L F}}+\underbrace{\int_{V} \overline{\rho_{r}^{H F}\left(z_{r}, t\right) g z_{r}(\rho, t)} \mathrm{d} V}_{B P E^{H F}},
\end{aligned}
$$

where $B P E^{M E A N}, B P E^{L F}$, and $B P E^{H F}$ are respectively the BPE associated with the mean, $L F$ and HF densities. The time evolution of the BPE is then the sum of the time evolution of the MEAN, LF, and HF BPE:

$$
\frac{d B P E}{d t}=\frac{d B P E^{\mathrm{MEAN}}}{d t}+\frac{d B P E^{\mathrm{LF}}}{d t}+\frac{d B P E^{\mathrm{HF}}}{d t},
$$

The evolution equation for the mean, LF or HF, BPE is:

$$
\frac{d B P E^{*}}{d t}=\int_{V} g \frac{\partial \rho_{r}^{*}}{\partial t} z_{r} \mathrm{~d} V+\underbrace{\int_{V} g \rho_{r}^{*} \frac{\partial z_{r}}{\partial t} \mathrm{~d} V}_{=0},
$$

where $*$ represents either MEAN, LF, or HF. The second term of the r.h.s. is zero as shown in Winters et al. (1995) and later in Tailleux (2009) because $\rho_{r}^{*}$ is constant on $z_{r}$ surfaces by construction (see Eq. (21)). 
and the forcing of the mean BPE is:

$$
F_{B P E^{M E A N}}=\int_{V} g \overline{z_{r}(\rho, t)} \bar{F} \mathrm{~d} V
$$


The advantage of this approach compared to that of Zemskova et al. (2015) is that the time independent heat flux forcing is entirely contained in $B P E^{M E A N}$ and that we have explicit equations for the densities associated with $B P E^{L F}$ and $B P E^{H F}$.

In the three MITgem configurations described in the following section 3, the diffusive processes increase the mean BPE $\left(D_{B P E^{*}}>0\right)$ and the surface heat flux forcing acts to decrease it $\left(F_{B P E^{M E A N}}<0\right)$. Because the APE varies in opposition to the BPE the above mentioned forcing and dissipation have respectively an increasing and decreasing impact on the APE. The sign of the forcing and dissipation of BPE is consistent with results from previous studies using BPE (Hughes et al. 2009; Zemskova et al. 2015).

\section{c. Available potential energy}

The mean APE budget is obtained as the difference between the mean PE (Eq. (9)) and the mean BPE (Eq. (26)) budgets:

$$
\begin{aligned}
& \frac{d A P E^{M E A N}}{d t}=\frac{d P E^{M E A N}}{d t}-\frac{d B P E^{M E A N}}{d t}= \\
& \underbrace{-C\left(A P E^{M E A N}, A P E^{L F}\right)}_{=-C\left(P E^{M E A N}, P E^{L F}\right)+C\left(B P E^{M E A N}, B P E^{L F}\right)=-C\left(P E^{M E A N}, P E^{H F}\right)+C\left(B P E^{M E A N}, B P E^{H F}\right)} \underbrace{-C\left(A P E^{M E A N}, A P E^{H F}\right)} \\
& \underbrace{-C\left(A P E^{M E A N}, K E^{M E A N}\right)}_{=-C\left(P E^{M E A N}, K E^{M E A N}\right)}+\underbrace{D_{A P E^{M E A N}}}_{=D_{P E^{M E A N}}-D_{B P E} M E A N}+\underbrace{F_{A P E^{M E A N}}}_{=-F_{B P E} M E A N}
\end{aligned}
$$

The conversion, dissipation and forcing terms of PE and BPE are derived in the two previous sections. Because $A P E^{M E A N}=P E^{M E A N}-B P E^{M E A N}$, the evolution terms of $B P E^{M E A N}$ appear in the $A P E^{M E A N}$ budget with a minus sign. $D_{A P E^{M E A N}}$ can then either be seen as the dissipation of mean APE or as the conversion between mean APE and mean BPE due to the time mean diffusive flux. Note that $D_{P E}$ MEAN does not explicitly appear in the BPE budget but it can be argued (see Hughes et al. 2009) that it contributes to the BPE budget and is thus added here as part of 


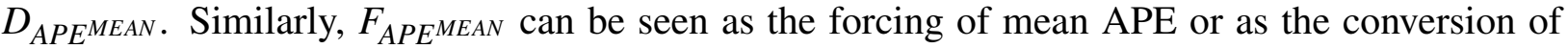
(mean) BPE to APE due to surface heat flux.

Because there is no potential energy in anomalies, APE in anomalies is only made of BPE. The LF APE budget is then:

$$
\begin{aligned}
& \frac{d A P E^{L F}}{d t}=\frac{d P E^{L F}}{d t}-\frac{d B P E^{L F}}{d t}= \\
& \underbrace{-C\left(A P E^{L F}, K E^{L F}\right)}_{=-C\left(P E^{L F}, K E^{L F}\right)}+\underbrace{C\left(A P E^{M E A N}, A P E^{L F}\right)}_{=C\left(P E^{M E A N}, P E^{L F}\right)-C\left(B P E^{M E A N}, B P E^{L F}\right)} \underbrace{-C\left(A P E^{L F}, A P E^{H F}\right)}_{=C\left(B P E^{L F}, B P E^{H F}\right)}+\underbrace{D_{A P E^{L F}}}_{=-D_{B P E}^{L F}} .
\end{aligned}
$$

Similarly, the HF APE budget is:

$$
\begin{aligned}
& \frac{d A P E^{H F}}{d t}=\frac{d P E^{H F}}{d t}-\frac{d B P E^{H F}}{d t}= \\
& \underbrace{-C\left(A P E^{H F}, K E^{H F}\right)}_{=-C\left(P E^{H F}, K E^{H F}\right)}+\underbrace{C\left(A P E^{M E A N}, A P E^{H F}\right)}_{=C\left(P E^{M E A N}, P E^{H F}\right)-C\left(B P E^{M E A N}, B P E^{H F}\right)}+\underbrace{C\left(A P E^{L F}, A P E^{H F}\right)}_{=-C\left(B P E^{L F}, B P E^{H F}\right)}+\underbrace{D_{A P E E^{H F}}}_{=-D_{B P E}{ }^{H F}} .
\end{aligned}
$$

\section{d. Kinetic Energy}

In this subsection, the budgets for the total and low frequency kinetic energy are derived. The horizontal momentum equations are:

$$
\begin{aligned}
& \frac{\partial u}{\partial t}+\mathbf{v} \cdot \nabla u-f v=-\frac{1}{\rho_{0}} \frac{\partial p}{\partial x}+V_{u}+F_{u} \\
& \frac{\partial v}{\partial t}+\mathbf{v} \cdot \nabla v+f u=-\frac{1}{\rho_{0}} \frac{\partial p}{\partial y}+V_{v}
\end{aligned}
$$

where $p$ is the pressure, $V_{u}$ and $V_{v}$ are the viscous term in respectively the zonal and meridional direction, $F_{u}$ is the zonal, time-independent forcing (we assume no meridional forcing) and $f$ is the Coriolis parameter. Time averaging Eqs. (38) and (39), multiplying by $\rho_{0} \bar{u}$ and $\rho_{0} \bar{v}$ and summing 


$$
\begin{gathered}
\frac{d K E^{L F}}{d t}=C\left(A P E^{L F}, K E^{L F}\right)+C\left(K E^{M E A N}, K E^{L F}\right)-C\left(K E^{L F}, K E^{H F}\right)+D_{K E^{L F}} \\
\frac{d K E^{H F}}{d t}=C\left(A P E^{H F}, K E^{H F}\right)+C\left(K E^{M E A N}, K E^{H F}\right)+C\left(K E^{L F}, K E^{H F}\right)+D_{K E^{H F}} \\
C\left(A P E^{L F}, K E^{L F}\right)=-\int_{V} g \overline{\rho^{L F} w^{L F}} \mathrm{~d} V
\end{gathered}
$$

Proceeding similarly for the LF and HF, we obtain the following budgets for $K E^{L F}$ and $K E^{H F}$ : 


$$
\begin{gathered}
C\left(A P E^{H F}, K E^{H F}\right)=-\int_{V} g \overline{\rho^{H F} w^{H F}} \mathrm{~d} V \\
C\left(K E^{L F}, K E^{H F}\right)=-\int_{V} \overline{\rho_{0} u^{H F} \nabla\left(\mathbf{u}^{\mathbf{H F}} u^{L F}\right)+\rho_{0} u^{H F} \nabla\left(\mathbf{u}^{\mathbf{H F}} u^{L F}\right)} \mathrm{d} V \\
D_{K E^{L F}}=\int_{V} \rho_{0} \overline{u^{L F} V_{u}^{L F}+\rho_{0} v^{L F} V_{v}^{L F}} \mathrm{~d} V \\
D_{K E^{H F}}=\int_{V} \rho_{0} \overline{u^{H F} V_{u}^{H F}+\rho_{0} v^{H F} V_{v}^{H F}} \mathrm{~d} V
\end{gathered}
$$

$$
D_{K E^{H F}}=-C(A P E, K E)-F_{K E^{M E A N}}-D_{K E^{M E A N}}-D_{K E^{L F}}
$$

$C\left(A P E^{H F}, K E^{H F}\right)$ can then be deduced from the knowledge of $C\left(A P E^{L F}, K E^{H F}\right)$ and $C\left(A P E^{M E A N}, K E^{M E A N}\right)$ :

$$
C\left(A P E^{H F}, K E^{H F}\right)=C(A P E, K E)-C\left(A P E^{L F}, K E^{H F}\right)-C\left(A P E^{M E A N}, K E^{M E A N}\right) .
$$

$D_{K E^{H F}}$ is obtained from the total KE budget: 
$D_{A P E^{H F}}$ is obtained using the total APE budget:

$$
D_{A P E^{H F}}=C(A P E, K E)-F_{A P E^{M E A N}}-D_{A P E^{M E A N}}-D_{A P E^{L F}} .
$$

Similarly, $C\left(K E^{L F}, K E^{H F}\right)$ is obtained from the $K E^{L F}$ budget, $C\left(K E^{M E A N}, K E^{H F}\right)$ from the $K E^{M E A N}$ budget, $C\left(A P E^{L F}, A P E^{H F}\right)$ from the $A P E^{L F}$ budget, and $C\left(A P E^{M E A N}, A P E^{H F}\right)$ from the $A P E^{M E A N}$ budget.

\section{Model and configuration}

We use the MITgcm (Marshall et al. 1997) in a rectangular flat-bottom basin with a Cartesian geometry on a $\beta$-plane centered at $40^{\circ} \mathrm{N}$. The zonal and meridional extents are respectively $L_{x}=5000 \mathrm{~km}$ and $L_{y}=4500 \mathrm{~km}$, and the Southern boundary is located $2000 \mathrm{~km}$ north of the equator. An eddy-permitting horizontal resolution of $20 \mathrm{~km}$ is used in both directions. This resolution is sufficient in Huck et al. (2015) to capture the main characteristics of the effect of eddy turbulence on low-frequency variability. The depth is $H=4500 \mathrm{~m}$, there are 40 levels on the vertical with grid spacing increasing from $10 \mathrm{~m}$ at the surface to $400 \mathrm{~m}$ at the bottom.

The ocean is forced by constant heat flux at the surface, decreasing linearly with latitude from $50 \mathrm{~W} \mathrm{~m}^{-2}$ at $y=0 \mathrm{~km}$ to $-50 \mathrm{~W} \mathrm{~m}^{-2}$ at $y=4500 \mathrm{~km}$, similar to Huck et al. (2015). Static instability is removed by strong vertical mixing of the water column. We use biharmonic horizontal eddy diffusivity with a uniform value of $10^{11} \mathrm{~m}^{4} \mathrm{~s}^{-1}$ and Leith implicit viscosity. The vertical viscosity is $v_{v}=10^{-3} \mathrm{~m}^{2} \mathrm{~s}^{-1}$. In this single hemisphere configuration, the strength of the Meridional Overturning Circulation (MOC) is a strong function of the vertical diffusivity $K_{v}$, in agreement with the $K_{v}^{1 / 2}$ geostrophic scaling (Huang and Chou 1994). Here, we choose to use $K_{v}=2 \times 10^{-4} \mathrm{~m}^{2} \mathrm{~s}^{-1}$ corresponding to a MOC strength close to $10 \mathrm{~Sv}$. Because the primary objective of this study is to establish and understand the full energy budget of the low-frequency mode in the configuration 
used in previous published articles (Huck et al. 1999, 2001, 2015; Hochet et al. 2020) our main experiment does not have wind forcing. However we also perform two additional experiments with increasing wind forcing intensity to study the effect of a direct KE source on the energy budget. The zonal wind stress used in the two wind forcing experiments varies with latitude according to the following formula:

$$
\tau_{x}(y)=\tau_{0}\left(\frac{1}{4} \cos \left(\frac{y \pi}{L_{y}}\right)-\cos \left(\frac{2 \pi y}{L_{y}}\right)\right),
$$

where $\tau_{0}$ is the wind stress amplitude. The meridional wind stress is zero. We chose to use a nonsymmetric zonal wind stress as it seems important to achieve a generic dynamical behavior of the double-gyre circulation (Berloff and McWilliams 1999). The three experiments use $\tau_{0}=0 \mathrm{Nm}^{-2}$ (no wind forcing), $\tau_{0}=0.05 \mathrm{~N} \mathrm{~m}^{-2}$ (intermediate wind) and $\tau_{0}=0.1 \mathrm{~N} \mathrm{~m}^{-2}$ (climatological wind) (Fig. 4). All three experiments are initialized with a state of rest, the spin-up time is then 500 years and the model is run for another 400 years to produce outputs to compute the diagnostics presented below.

\section{Time mean circulation and variability}

In the following section we describe the time mean circulation as well as the low and high frequency variability obtained for the range of surface wind-stress forcing amplitudes mentioned above. Hochet et al. (2020) used exactly the same model parameters and configuration as the present study with zero wind-stress forcing. The turbulent transfer of temperature variance in their study was shown to act as a source of temperature variance for frequencies higher than $1 / 3.5$ years and a sink for smaller frequencies. We thus define the limit between low and high frequencies as being $3.5 \mathrm{yr}$. Although it is possible that this limit is altered by the surface wind stress that we use in the two other experiments, we keep the same definition of 1/3.5 years in all experiments to be able to compare the three configurations. We thus associate LF with multi-decadal, decadal 
and part of the inter-annual variability and HF with part of the inter-annual and eddy turbulence induced variability.

a. No wind forcing $\tau_{0}=0 \mathrm{Nm}^{-2}$

Note that the simulation used in this subsection (i.e. without wind forcing) is the same as that described in Hochet et al. (2020), and the description of the LF variability is reproduced below. In the absence of wind-stress forcing, LF variability spontaneously develops with a significant and narrow peak frequency of $1 / 53 \mathrm{yr}^{-1}$ (Fig. 5). A detailed description of the variability developing in very similar geometries can be found for instance in Huck et al. (1999) and Huck et al. (2015). Here we will only give a short description of its main characteristics. Following Hochet et al. (2020), we use Complex Empirical Orthogonal Function (CEOF) to describe the LF variability of the three dimensional temperature field. The CEOF are calculated using 50-day average outputs on a 400-year long simulation. The 400 year is chosen to obtain a statistical equilibrium of the solution. Similar to the widely used empirical orthogonal function, CEOF are the eigenvectors of the complex covariance matrix of a complex temperature anomaly which is calculated using the Hilbert transform of the detrended temperature anomaly (Von Storch and Zwiers 2001). The leading CEOF contains $60 \%$ of the temperature variance (Fig. 6). The temperature anomaly associated to a CEOF can then be reconstructed using the following formula:

$$
\theta_{\mathrm{CEOF}}(x, y, z, t)=\mathrm{PC}_{r e}(t) \mathrm{CEOF}_{r e}(x, y, z)+\mathrm{PC}_{i m}(t) \mathrm{CEOF}_{i m}(x, y, z)
$$

where re and im stand for the real and imaginary parts respectively and PC is the principal component of the corresponding CEOF. The APE is shown along with the real and imaginary part of the PC (Fig. 6). The phase of the leading CEOF is chosen to match that of the APE time variation. The APE is very well correlated with the real part of the PC and shows that APE multidecadal vari- 
ations are linked with the SST pattern shown on the upper panel of figure 6. The low-frequency variability takes the form of a large-scale temperature anomaly, located mainly in the northwestern half and in the upper $500 \mathrm{~m}$ of the basin with SST anomaly larger than $3 \mathrm{~K}$ at some locations (Fig. 6). The successive positions of the positive and negative temperature anomalies as shown on figure 6, i.e. a negative center located at latitudes around $2500-3000 \mathrm{~km}$ and longitude $2000 \mathrm{~km}$ (opposite of the imaginary part), followed by a negative center for latitudes between 3000 and $3500 \mathrm{~km}$, longitude around $2000 \mathrm{~km}$ (real part), then a negative center around latitude $4000 \mathrm{~km}$, longitude $1500 \mathrm{~km}$ (imaginary part), then a negative center in the north western corner (opposite of the real part), indicate north-westward propagation of the temperature anomalies.

The sea surface height ( $\mathrm{SSH}$ ) varies together with the temperature anomalies of the leading CEOF (left column of Fig. 7). The amplitude of SSH anomalies $(15-20 \mathrm{~cm})$ is maximum along the western boundary current and in its eastward extension in the northern-half of the basin. These values compare well with altimetric observations (Stammer 1997). The time mean of the vertical integral of the LF APE and of the LF density variance are shown in figure 7. The largest values for the LF APE are located along the northern boundary. Equation (22) shows that large values of LF APE (=-LF BPE) are associated with deep reference depth and thus outcropping of dense waters. The location of LF APE contrasts with the location of the largest values of LF density variance which are located in the northern part of the basin interior (Fig. 7). The differences between these two quantities further demonstrate that the APE cannot be approximated by the density variance in these configurations in contrast with QG theory.

\section{b. Intermediate wind forcing $\tau_{0}=0.05 \mathrm{Nm}^{-2}$}

When wind-stress forcing is present the temperature variability is significantly reduced compared to the previous case and consists of a broad band of low-frequency signals with a peak 
frequency of about $1 / 22 \mathrm{yr}^{-1}$ (Fig. 5). Huck et al. (2001) explained this effect of the wind forcing on the low frequency variability by the damping effect of the Ekman pumping on the large-scale anomalies. To explain this effect, Huck et al. (2001) assumed that the following formula describes the effect of wind stress on the temperature anomalies (their equation (14)):

$$
\frac{\partial \theta^{\prime}}{\partial t}=-W_{E} \frac{\partial \theta^{\prime}}{\partial z}
$$

where $\theta^{\prime}$ is the temperature anomaly, and $W_{E}$ the Ekman pumping. Then if $\theta^{\prime}$ is further assumed to have an exponential profile with depth, $\theta^{\prime} \propto \exp \left(-W_{E} k t\right)$ with $k$ of the order of $500 \mathrm{~m}^{-1}$. The temperature anomaly decreases where $W_{E}$ is positive which is in the Northern half of the basin in our configuration.

The surface signature of the leading CEOF of temperature variability, explaining $28 \%$ of the spatially integrated variance, shows that the variability now occurs predominantly along the eastern boundary and along a narrow latitudinal band extending across the width of the basin just south of the intergyre boundary (Fig. 8). The large-scale anomaly emanates from the eastern boundary and propagates to the west along the mean temperature contours. SSH variability is no longer collocated with SST variations, as was the case with zero wind-stress forcing, but instead mostly occurs along a region centered about the intergyre (at $y=2000 \mathrm{~km}$ ) along the western boundary (Fig. 7, second row). The LF density variance is now almost entirely located on the eastern boundary as also shown by the CEOF (Fig. 8). The LF APE is in the northeastern corner of the basin in the region where dense waters outcrop.

\section{c. Climatological wind forcing $\tau_{0}=0.1 \mathrm{Nm}^{-2}$}

Increasing the amplitude of the zonal surface wind-stress forcing up to realistic values has the effect of further decreasing (increasing) the temperature variance on interdecadal (monthly 
to interannual) timescales compared to the case with $\tau_{0}=0.05 \mathrm{Nm}^{-2}$. Indeed the volume averaged LF (HF) temperature spectrum (defined as frequencies lower than $\frac{2 \pi}{3.5 y e a r s}$ ) is weaker for $\tau_{0}=0.05 \mathrm{Nm}^{-2}$ than for $\tau_{0}=0.1 \mathrm{Nm}^{-2}$ (Fig. 5).

The leading CEOF of temperature variability now represents only $7 \%$ of the spatially-integrated variance and is mostly apparent south of the intergyre boundary (Fig. 9). This pattern of variability differs from the previous case with $\tau_{0}=0.05 \mathrm{Nm}^{-2}$ (Fig. 8) for which SST variability was also present along the eastern boundary. SSH variability however shares the same pattern and amplitude as that obtained for $\tau_{0}=0.05 \mathrm{~N} \mathrm{~m}^{-2}$ with enhanced variability along the western boundary current. The LF APE is now located in the northwestern part of the basin with a much smaller amplitude than in the two previous cases.

\section{Energy budget}

We now describe the mean, LF, and HF KE, APE and BPE budgets for the three experiments described above, summarized in figures 10,12, and 13 following the schematic given in figure 3 . Table 2 gathers the transfer values obtained for the three experiments.

a. No-wind forcing $\tau_{0}=0 \mathrm{Nm}^{-2}$

In the absence of surface wind-stress there is no external source for the KE reservoir and the main energy pathways are located within the APE part of the budget (Fig. 10). Among the $119 \mathrm{GW}$ of conversion between BPE and APE due to surface heat flux $32 \mathrm{GW}$ is converted into KE (mainly at $\mathrm{HF}$ ) where it is dissipated by viscous forces. The remaining $87 \mathrm{GW}$ are mainly transferred from HF APE to BPE because of dissipation (53 GW from APE HF to BPE, 16GW from LF APE to BPE and $18 \mathrm{GW}$ from mean APE to BPE). 
Despite the differences between BPE and density variance shown in figure 7, Hochet et al. (2020) found a similar pathway for the temperature variance. The surface heat flux is the only source of mean temperature variance and LF temperature variance is forced through a transfer of temperature variance from the mean flow, this transfer is interpreted as the result of baroclinic instability of the mean flow. The conversion from mean APE to LF APE is 49GW which is the largest conversion term in this experiment. The main sink of LF APE is the conversion to HF APE (29 GW), whereas the dissipation removes $16 \mathrm{GW}$. Because the direction of the $\mathrm{LF} / \mathrm{HF}$ APE transfer is from $\mathrm{LF}$ to $\mathrm{HF}$ and because LF are associated with large scales and HF with mesoscale eddies, we deduce that mesoscale eddy turbulence is a sink of energy for the low-frequency variability which is one of the main result of this study. It confirms previous findings of Arbic et al. (2014) who demonstrated the existence of a direct temporal APE cascade along with the inverse temporal KE cascade under QG approximation. Conversion between kinetic energy reservoirs is small compared to conversion between APE reservoirs. There is however a substantial energy transfer $(20 \mathrm{GW})$ between HF APE and HF KE. This input of HF KE is balanced by the sink linked with viscous terms. The only source of mean $\mathrm{KE}$ is the conversion of mean APE to mean $\mathrm{KE}(8 \mathrm{GW})$ and the conversion between LF and HF KE is negligible. The ratio of LF KE to LF APE is of $0.3 \%$ showing that the low frequency variability is predominantly found in APE in this simulation.

The two left columns of Fig. 11 show the spatial pattern of $C\left(A P E^{M E A N}, A P E^{H F}\right)$, $C\left(A P E^{M E A N}, A P E^{L F}\right)$ integrated vertically over the water column. Strong positive values of these two terms are generally located close to the northern boundary, where the convection is the strongest. Positive values of $C\left(A P E^{M E A N}, A P E^{H F}\right)$ are located in the eastern part of the northern boundary and follows closely the values of mean APE forcing (last column of Fig. 11). Negative values are located in the southern part of the basin interior. The mean APE forcing term is large in regions where the reference level is the deepest i.e. where dense waters outcrop at the surface. 
$C\left(A P E^{M E A N}, A P E^{L F}\right)$ (Fig. 11, middle-left column) has its largest values close to the northern and eastern boundary. The vertical integral of the term $-\overline{\mathbf{u}^{\mathbf{L F}} \rho^{\mathbf{L F}}} \cdot \nabla \bar{\rho}$ which represents the transfer from the mean to the LF density variance (see Colin de Verdière and Huck 1999, for instance) is shown on the third column of figure 11 and is very different from $C\left(A P E^{M E A N}, A P E^{L F}\right)$. This could be expected from the difference between the variance of the LF density and the LF APE already shown in figure 7: the transfer from mean APE to LF APE occurs in the convection region where dense waters outcrop whereas the LF density variance transfer occurs in the basin interior. $C\left(A P E^{L F}, A P E^{H F}\right)$ is not shown but follows closely the variation of $C\left(A P E^{M E A N}, A P E^{L F}\right)$.

\section{b. Intermediate wind forcing $\tau_{0}=0.05 \mathrm{~N} \mathrm{~m}^{-2}$}

With an intermediate zonal wind stress at the surface, the LF variability becomes weaker and shifts to mid-latitudes as explained in section 4 b. The energy budget (Fig. 12) shows a decrease of the energy fluxes from mean APE and LF APE. The transfer of BPE to mean APE is the same as that obtained for the no-wind experiment $(119 \mathrm{GW})$. Part of this mean APE energy input is transferred back to BPE by parametrized diffusive flux $(30 \mathrm{GW})$ whereas most of it is converted into HF APE (61GW). The conversion of LF APE to HF APE is approximately half the value obtained for the no-wind case (14GW against $29 \mathrm{GW}$ ). The total transfer (i.e. KE+APE) is still directed from LF toward HF. There is now a small direct forcing of mean KE (7GW) which adds to the conversion from mean APE to mean KE $(5 \mathrm{GW})$ to create a source of $12 \mathrm{GW}$ of Mean KE. $8 \mathrm{GW}$ is directly dissipated by viscous forces, the remaining is mainly transferred to HF KE. The conversion between LF KE and HF KE is negligible.

The ratio of LF KE and LF APE has increased compared with the no wind simulation (the ratio is now 1\%), however LF KE remains negligible compared to LF APE. We explain the predominance of APE over KE in the LF by the larger scales found at these frequencies. It is indeed known 
from QG theory that the ratio KE over APE decreases with larger scales (Vallis 2017). Using the ECCO2 ocean state estimate, Zemskova et al. (2015) found that there is approximately 10 times more APE than KE in anomalies but do not discriminate between frequency bands which make the comparison with our results difficult.

With wind forcing, the $C\left(A P E^{M E A N}, A P E^{H F}\right)$ conversion increases by $17 \mathrm{GW}$ (Table 2), its positive values follow the northern boundary of the basin (Fig. 11) and the mean APE forcing (last column of Fig. 11). The largest values of $C\left(A P E^{M E A N}, A P E^{L F}\right)$ are now almost entirely located in the northeastern corner where the SST anomalies seem to originate from.

\section{c. Climatological wind forcing $\tau_{0}=0.1 \mathrm{~N} \mathrm{~m}^{-2}$}

In this experiment the zonal wind forcing is twice as strong as in the previous experiment, close to the climatological amplitude. The wind stress adds $34 \mathrm{GW}$ to the mean $\mathrm{KE}$ reservoir and $15 \mathrm{GW}$ is directly dissipated by viscous forces (Fig. 13). The conversion from mean APE to mean KE is now negative (i.e. from mean KE to mean APE) which is in line with what is calculated in OGCM (e.g. Toggweiler and Samuels 1998; Gnanadesikan et al. 2005; Gregory and Tailleux 2011). The remaining $8 \mathrm{GW}$ are all converted to HF KE. The conversion of BPE to mean APE due to heat flux has slightly increased compared to the two other experiments $(128 \mathrm{GW})$. The BPE to mean APE conversion formula $-g \int_{V} \overline{z_{r}(\rho, t)} \bar{F} \mathrm{~d} V$ shows that the value of this conversion mainly depends on the position of the deepest reference depths and thus on the circulation in the Northern half of the basin. An explanation for the (small) increase in BPE to mean APE conversion could thus be that only the climatological wind substantially modifies the circulation in this region. The conversion from mean APE to HF APE is now much larger than the conversion from mean APE to LF APE ( $84 \mathrm{GW}$ vs $13 \mathrm{GW}), 42 \mathrm{GW}$ is directly dissipated. The energy in the LF KE reservoir has increased compared to the two other simulation and now represents $10 \%$ of LF APE. 
With this realistic amplitude of wind forcing, positive values of the conversion $C\left(A P E^{M E A N}, A P E^{H F}\right)$ continue to extend along the northern boundary (Fig. 11 bottom line) and is particularly intense in the northwestern corner. $C\left(A P E^{M E A N}, A P E^{L F}\right)$ intensity is weaker than before and almost entirely located in the northwestern corner.

Sohail et al. (2018) and Zemskova et al. (2021) report that the input of KE obtained by increasing the wind stress over the Southern ocean results mainly in an increase of the KE dissipation term, rather than an increase in APE dissipation. These results are in line with what is found in our experiments: the total dissipation of $\operatorname{KE}\left(D_{K E^{M E A N}}+D_{K E^{L F}}+D_{K E^{H F}}\right)$ has increased by $65 \%$ between the no-wind and climatological wind experiment and by $24 \%$ for the total dissipation of $\operatorname{APE}\left(D_{A P E^{M E A N}}+D_{A P E^{L F}}+D_{A P E^{H F}}\right):$ most of the additional mean $\mathrm{KE}$ forcing is directly dissipated by KE total dissipation.

\section{Conclusion}

In this article we have derived the mechanical energy budget for the large-scale, internally generated, low-frequency ocean mode that was studied extensively in previous works (Colin de Verdière and Huck 1999; Huck et al. 1999; Huck and Vallis 2001; Huck et al. 2001, 2015; Arzel et al. 2018; Hochet et al. 2020). The mechanical energy budget is decomposed into mean, low-frequency, and high-frequency parts to study the effect of the large-scale baroclinic instability of the mean circulation and the effect of the eddy field on the LF mode. One of the main achievements of this work is the new way of decomposing the background potential energy into frequency bands that allows us to correctly attribute the source and sink terms associated with each reservoir.

The energy budget of the no wind experiment shows that the energy of this multidecadal mode is mostly contained in the LF APE rather than in the LF KE because of its large-scale. Using ECCO v2, Zemskova et al. (2015) also found that the energy is mostly contained in the fluctuating 
APE rather than in the fluctuating KE, but with a smaller ratio of approximately 10 (compared to a LF APE over LF KE ratio of approximately 300 in our no wind experiment). This difference is probably due to our use of a single hemispheric basin and thus to the omission of the strong wind forcing over the Southern ocean. The source term for the LF APE is the conversion from the mean APE to the LF APE. In agreement with Hochet et al. (2020) where the budget was made in terms of temperature variance, the sink term of the mode is attributed to the parametrized diffusion $(\sim$ $36 \%)$ and to the transfer of APE to higher-frequencies linked with mesoscale eddy turbulence $(\sim$ $64 \%)$. In the experiment with no wind forcing, the only source of kinetic energy is the conversion from APE at all frequencies. The transfer of KE between high and low-frequencies which is shown to be an important source of low frequency variability in other experiments (Arbic et al. 2014; Sérazin et al. 2018) appears negligible in our configuration compared to all the other energy fluxes. Recognising that this might be due to the absence of any direct source of kinetic energy we performed two other experiments with a time independent zonal wind forcing at the surface that drives the classical wind-driven double gyres.

With the addition of a wind forcing at the surface, a source term for the mean kinetic energy appears. The structure of the LF mode is modified with intermediate wind strength and almost disappears with climatological wind. With increasing wind forcing, the LF APE and all its associated conversion terms decrease. Indeed there is a decrease in the values of the conversion terms from mean APE to LF APE and of LF APE to BPE (linked with diffusive flux), of LF APE to HF APE and of LF APE to LF KE for the sink terms. Meanwhile, the energy in the HF APE increases as well as the conversion from mean APE to HF APE. This larger conversion is balanced mostly by a larger conversion of HF APE to BPE due to diffusive flux. The energy contained in the mean APE increases as well as the conversion from BPE to mean APE due to heat flux. This increase is balanced by a larger conversion to BPE due to diffusive flux and by a larger conversion 
to HF APE. The conversion of mean APE to mean KE becomes negative which is in agreement with what is usually calculated in more realistic models such as in Zemskova et al. (2015). The conversion between LF KE and HF KE remains negligible or very small compared to other conversions, nonetheless, it is directed from HF to LF for the climatological wind experiment which is in agreement with the temporal inverse KE cascade found in Arbic et al. (2014).

For all wind stress intensities studied here, the energy and conversion terms remain mainly contained in the APE. There is however a non-negligible transfer of APE to KE at HF where it is dissipated by viscous forces. The fact that most of the transfers of energy occur between the different APE and BPE reservoirs rather than between PE or KE reservoirs outline the importance of the APE budget to study large-scale and low frequency variability. In contrast, Arbic et al. (2014); Sérazin et al. $(2015,2018)$ found a predominant role for the temporal inverse KE cascade, but we attribute this difference for the most part to our focus on multidecadal variability as compared to their focus on shorter inter-annual variability. The transfer from LF APE to HF APE demonstrates the damping role of the mesoscale eddy turbulence for the large scale variability, even for realistic wind intensities. This transfer of APE from LF to HF is very similar to the QG APE direct temporal cascade of APE that has been observed (along with the inverse temporal cascade of KE) in the idealized simulation of Arbic et al. (2014). Temperature variance budget gives similar pathway for the sources and sinks of the low frequency mode (Hochet et al. 2020). However, we have shown that the locations of the APE and of its associated transfers differ significantly from that of the density variance. Large values of APE are indeed linked with the outcropping of dense waters at the surface due to convection that occurs along the northern boundary in our configuration, whereas there is no significant link between large values of density variance and convective regions. The APE budget is therefore more accurate in identifying regions where energy conversions are the most important. 
This study is limited by several approximations, the first being the representation of the North Atlantic ocean with a simplified geometry and a flat bottom. In particular, the wind forcing over the Southern Ocean is thought to play an important role in setting the mean stratification, in particular the stratification in the North Atlantic (e.g. Nikurashin and Vallis 2011,2012) and might therefore influence the dynamic of the low frequency mode. Moreover, using energy budget of a global ocean-sea ice model Hogg et al. (2017) have shown that wind change over the Southern Ocean leads to change of APE and stratification in the North Atlantic. However, it has been shown in Arzel et al. (2007) that the addition of a re-entrant channel representing the Antarctic Circumpolar Current acts to reduce the low frequency variability in the Southern Hemisphere but does not suppress the internal variability in the Northern Hemisphere. Moreover, the physical mechanism giving rise to the internal mode studied in this single hemispheric configuration is also found to give rise to low-frequency variability in realistic ocean-only configuration (e.g. Sévellec and Fedorov 2013; Arzel et al. 2018; Arzel and Huck 2020) and in ocean-atmosphere coupled configuration (e.g. Ortega et al. 2015; Gastineau et al. 2018). The omission of salinity and the use of a linear equation of state for density certainly has an influence on the APE budget. Indeed, it is known that non-linearities of the equation of state are in general not negligible (e.g. Klocker and McDougall 2010; Nycander et al. 2015). Nonetheless, it has been shown in a realistic setup (Sévellec and Fedorov 2013) that the mode is largely controlled by temperature variation in the upper ocean. Our study as well as previous studies of the internal mode (e.g. Sévellec and Fedorov 2013; Huck et al. 2015; Arzel et al. 2018) assume that external forcing is either constant or made of natural variability such as the North Atlantic Oscillation (Frankcombe et al. 2009; Arzel and Huck 2020). This assumption is helpful to understand the physics and the mechanisms of the mode. However, with its multi-decadal variability, the internal mode might be affected by anthro- 
pogenic forcing which act on the same time scales and modifies the characteristics of the ocean stratification (Levitus et al. 2012).

The eddy-permitting resolution of $20 \mathrm{~km}$ used here is not sufficient to entirely resolve the eddy field, however similar experiments at $10 \mathrm{~km}$ with no wind forcing were conducted in Huck et al. (2015) and no qualitative differences were found. Lastly we set the limit between LF and HF to be 3.5 years based on the results from Hochet et al. (2020) that showed that in the same configuration without wind forcing, non-linear transfers of temperature variance are a source (sink) term for periods longer (shorter) than 3.5 years. To be able to compare the three configurations studied in this article we kept this limit fixed, however, with the addition of a wind forcing at the surface, we expect a change in this limit and possibly a modification of the LF/HF transfers. The study of the dependence of this limit on external parameters is left to future work, as well as the implementation of this full energy budget in realistic eddy-resolving models.

Acknowledgments. This study was supported by a EU Marie Curie IF grant number 749924 . Numerical computations were conducted using the Pôle de Calcul Intensif pour la Mer at Ifremer, Brest, France. We thank the MITgcm development group for making their model freely available. We also thank three anonymous reviewers for their comments and suggestions, which helped to improve the manuscript.

\section{References}

Arbic, B. K., M. Müller, J. G. Richman, J. F. Shriver, A. J. Morten, R. B. Scott, G. Sérazin, and T. Penduff, 2014: Geostrophic turbulence in the frequency-wavenumber domain: Eddy-driven low-frequency variability. Journal of Physical Oceanography, 44 (8), 2050-2069. 
Arzel, O., A. Colin de Verdière, and T. Huck, 2007: On the origin of interdecadal oscillations in a coupled ocean atmosphere model. Tellus A, 59 (3), 367-383.

Arzel, O., and T. Huck, 2020: Contributions of atmospheric stochastic forcing and intrinsic ocean modes to North Atlantic ocean interdecadal variability. Journal of Climate, 33 (6), 2351-2370.

Arzel, O., T. Huck, and A. Colin de Verdière, 2018: The internal generation of the Atlantic ocean interdecadal variability. Journal of Climate, 31 (16), 6411-6432, doi:10.1175/JCLI-D-17-0884. 1.

Berloff, P. S., and J. C. McWilliams, 1999: Large-scale, low-frequency variability in wind-driven ocean gyres. Journal of Physical Oceanography, 29 (8), 1925-1949.

Booth, B. B., N. J. Dunstone, P. R. Halloran, T. Andrews, and N. Bellouin, 2012: Aerosols implicated as a prime driver of twentieth-century North Atlantic climate variability. Nature, 484 (7393), 228-232.

Buckley, M. W., D. Ferreira, J.-M. Campin, J. Marshall, and R. Tulloch, 2012: On the relationship between decadal buoyancy anomalies and variability of the Atlantic meridional overturning circulation. Journal of Climate, 25 (23), 8009-8030.

Clement, A., K. Bellomo, L. N. Murphy, M. A. Cane, T. Mauritsen, G. Rädel, and B. Stevens, 2015: The Atlantic Multidecadal Oscillation without a role for ocean circulation. Science, 350 (6258), 320-324.

Clement, A., M. A. Cane, L. N. Murphy, K. Bellomo, T. Mauritsen, and B. Stevens, 2016: Response to Comment on "The Atlantic Multidecadal Oscillation without a role for ocean circulation”. Science, 352 (6293), 1527-1527, doi:10.1126/science.aaf2575. 
Colin de Verdière, A., and T. Huck, 1999: Baroclinic instability: An oceanic wavemaker for interdecadal variability. Journal of Physical Oceanography, 29 (5), 893-910.

Deser, C., M. A. Alexander, S.-P. Xie, and A. S. Phillips, 2010: Sea surface temperature variability: Patterns and mechanisms. Annual review of marine science, 2, 115-143.

Frankcombe, L., H. Dijkstra, and A. Von der Heydt, 2008: Sub-surface signatures of the atlantic multidecadal oscillation. Geophysical Research Letters, 35 (19).

Frankcombe, L. M., H. A. Dijkstra, and A. Von der Heydt, 2009: Noise-induced multidecadal variability in the North Atlantic: Excitation of normal modes. Journal of Physical Oceanography, 39 (1), 220-233.

Frankignoul, C., and K. Hasselmann, 1977: Stochastic climate models, Part II Application to sea-surface temperature anomalies and thermocline variability. Tellus, 29 (4), 289-305.

Gastineau, G., J. Mignot, O. Arzel, and T. Huck, 2018: North Atlantic Ocean Internal Decadal Variability: Role of the Mean State and Ocean-Atmosphere Coupling. Journal of Geophysical Research: Oceans, 123 (8), 5949-5970.

Gnanadesikan, A., R. D. Slater, P. S. Swathi, and G. K. Vallis, 2005: The energetics of ocean heat transport. Journal of climate, 18 (14), 2604-2616.

Greatbatch, R. J., and S. Zhang, 1995: An interdecadal oscillation in an idealized ocean basin forced by constant heat flux. Journal of climate, 8 (1), 81-91.

Grégorio, S., T. Penduff, G. Sérazin, J.-M. Molines, B. Barnier, and J. Hirschi, 2015: Intrinsic variability of the atlantic meridional overturning circulation at interannual-to-multidecadal time scales. Journal of Physical Oceanography, 45 (7), 1929-1946. 
Gregory, J. M., and R. Tailleux, 2011: Kinetic energy analysis of the response of the Atlantic meridional overturning circulation to $\mathrm{CO} 2$-forced climate change. Climate dynamics, 37 (5-6), 893-914.

Gulev, S. K., M. Latif, N. Keenlyside, W. Park, and K. P. Koltermann, 2013: North atlantic ocean control on surface heat flux on multidecadal timescales. Nature, 499 (7459), 464-467.

Hasselmann, K., 1976: Stochastic climate models part I. Theory. tellus, 28 (6), 473-485.

Hochet, A., T. Huck, O. Arzel, F. Sévellec, A. Colin de Verdière, M. Mazloff, and B. Cornuelle, 2020: Direct temporal cascade of temperature variance in eddy-permitting simulations of multidecadal variability. Journal of Climate, 33 (21), 9409-9425.

Hogg, A. M., P. Spence, O. A. Saenko, and S. M. Downes, 2017: The energetics of southern ocean upwelling. Journal of Physical Oceanography, 47 (1), 135-153.

Huang, R. X., and R. L. Chou, 1994: Parameter sensitivity study of the saline circulation. Climate Dynamics, 9 (8), 391-409.

Huck, T., O. Arzel, and F. Sévellec, 2015: Multidecadal variability of the overturning circulation in presence of eddy turbulence. Journal of Physical Oceanography, 45 (1), 157-173.

Huck, T., A. Colin de Verdière, and A. J. Weaver, 1999: Interdecadal variability of the thermohaline circulation in box-ocean models forced by fixed surface fluxes. Journal of physical oceanography, 29 (5), 865-892.

Huck, T., and G. K. Vallis, 2001: Linear stability analysis of the three-dimensional thermallydriven ocean circulation: application to interdecadal oscillations. Tellus A, 53 (4), 526-545.

Huck, T., G. K. Vallis, and A. Colin de Verdière, 2001: On the robustness of the interdecadal modes of the thermohaline circulation. Journal of climate, 14 (5), 940-963. 
Hughes, G. O., A. M. C. Hogg, and R. W. Griffiths, 2009: Available potential energy and irreversible mixing in the meridional overturning circulation. Journal of Physical Oceanography, 39 (12), 3130-3146.

Jamet, Q., W. Dewar, N. Wienders, and B. Deremble, 2019: Spatiotemporal patterns of chaos in the atlantic overturning circulation. Geophysical Research Letters, 46 (13), 7509-7517.

Jamet, Q., T. Huck, O. Arzel, J.-M. Campin, and A. C. de Verdière, 2016: Oceanic control of multidecadal variability in an idealized coupled GCM. Climate Dynamics, 46 (9-10), 30793095, doi:10.1007/s00382-015-2754-3.

Kerr, R. A., 2000: A north atlantic climate pacemaker for the centuries. Science, 288 (5473), 1984-1985.

Klocker, A., and T. J. McDougall, 2010: Influence of the nonlinear equation of state on global estimates of dianeutral advection and diffusion. Journal of Physical Oceanography, 40 (8), 1690-1709.

Kushnir, Y., 1994: Interdecadal variations in North Atlantic sea surface temperature and associated atmospheric conditions. Journal of Climate, 7 (1), 141-157.

Leroux, S., T. Penduff, L. Bessières, J.-M. Molines, J.-M. Brankart, G. Sérazin, B. Barnier, and L. Terray, 2018: Intrinsic and atmospherically forced variability of the amoc: Insights from a large-ensemble ocean hindcast. Journal of Climate, 31 (3), 1183-1203.

Levitus, S., and Coauthors, 2012: World ocean heat content and thermosteric sea level change (0-2000 m), 1955-2010. Geophysical Research Letters, 39 (10).

Lorenz, E. N., 1955: Available potential energy and the maintenance of the general circulation. Tellus, 7 (2), 157-167. 
Marshall, J., A. Adcroft, C. Hill, L. Perelman, and C. Heisey, 1997: A finite-volume, incompressible Navier Stokes model for studies of the ocean on parallel computers. Journal of Geophysical Research: Oceans, 102 (C3), 5753-5766.

Martin, P. E., B. K. Arbic, A. McC. Hogg, A. E. Kiss, J. R. Munroe, and J. R. Blundell, 2020: Frequency-domain analysis of the energy budget in an idealized coupled ocean-atmosphere model. Journal of Climate, 33 (2), 707-726.

Muir, L. C., and A. V. Fedorov, 2017: Evidence of the amoc interdecadal mode related to westward propagation of temperature anomalies in cmip5 models. Climate Dynamics, 48 (5-6), 1517 1535

Nikurashin, M., and G. Vallis, 2011: A theory of deep stratification and overturning circulation in the ocean. Journal of Physical Oceanography, 41 (3), 485-502.

Nikurashin, M., and G. Vallis, 2012: A theory of the interhemispheric meridional overturning circulation and associated stratification. Journal of Physical Oceanography, 42 (10), 16521667.

Nycander, J., M. Hieronymus, and F. Roquet, 2015: The nonlinear equation of state of sea water and the global water mass distribution. Geophysical Research Letters, 42 (18), 7714-7721.

Ortega, P., J. Mignot, D. Swingedouw, F. Sévellec, and E. Guilyardi, 2015: Reconciling two alternative mechanisms behind bi-decadal variability in the North Atlantic. Progress in Oceanography, 137, 237-249.

Penduff, T., M. Juza, B. Barnier, J. Zika, W. K. Dewar, A.-M. Treguier, J.-M. Molines, and N. Audiffren, 2011: Sea level expression of intrinsic and forced ocean variabilities at interannual time scales. Journal of Climate, 24 (21), 5652-5670. 
Reguero, B. G., I. J. Losada, and F. J. Méndez, 2019: A recent increase in global wave power as a consequence of oceanic warming. Nature communications, 10 (1), 1-14.

Saenz, J. A., R. Tailleux, E. D. Butler, G. O. Hughes, and K. I. Oliver, 2015: Estimating Lorenz's reference state in an ocean with a nonlinear equation of state for seawater. Journal of Physical Oceanography, 45 (5), 1242-1257.

Schlesinger, M. E., and N. Ramankutty, 1994: An oscillation in the global climate system of period 65-70 years. Nature, 367 (6465), 723-726.

Scotti, A., and B. White, 2014: Diagnosing mixing in stratified turbulent flows with a locally defined available potential energy. Journal of Fluid Mechanics, 740, 114-135.

Sévellec, F., A. C. N. Garabato, and T. Huck, 2020: Damping of climate-scale oceanic variability by mesoscale eddy turbulence. Journal of Physical Oceanography, doi:10.1175/ JPO-D-20-0141.1, URL https://journals.ametsoc.org/view/journals/phoc/aop/JPO-D-20-0141. 1/JPO-D-20-0141.1.xml.

Sohail, T., B. Gayen, and A. M. Hogg, 2018: Convection enhances mixing in the southern ocean. Geophysical Research Letters, 45 (9), 4198-4207.

Spall, M. A., 2008: Low-frequency interaction between horizontal and overturning gyres in the ocean. Geophysical Research Letters, 35 (18), doi:https://doi.org/10.1029/2008GL035206.

Stammer, D., 1997: Global characteristics of ocean variability estimated from regional TOPEX/POSEIDON altimeter measurements. Journal of Physical Oceanography, 27 (8), 1743-1769. 
Sutton, R. T., G. D. McCarthy, J. Robson, B. Sinha, A. T. Archibald, and L. J. Gray, 2018: Atlantic multidecadal variability and the UK ACSIS program. Bulletin of the American Meteorological Society, 99 (2), 415-425.

Sérazin, G., T. Penduff, B. Barnier, J.-M. Molines, B. K. Arbic, M. Müller, and L. Terray, 2018: Inverse Cascades of Kinetic Energy as a Source of Intrinsic Variability: A Global OGCM Study. Journal of Physical Oceanography, 48 (6), 1385-1408.

Sérazin, G., T. Penduff, S. Grégorio, B. Barnier, J.-M. Molines, and L. Terray, 2015: Intrinsic variability of sea level from global ocean simulations: Spatiotemporal scales. Journal of Climate, 28 (10), 4279-4292.

Sévellec, F., and A. V. Fedorov, 2013: The leading, interdecadal eigenmode of the Atlantic meridional overturning circulation in a realistic ocean model. Journal of Climate, 26 (7), 2160-2183.

Tailleux, R., 2009: On the energetics of stratified turbulent mixing, irreversible thermodynamics, Boussinesq models and the ocean heat engine controversy. Journal of Fluid Mechanics, 638, 339-382.

Te Raa, L. A., and H. A. Dijkstra, 2002: Instability of the thermohaline ocean circulation on interdecadal timescales. Journal of physical oceanography, 32 (1), 138-160.

Toggweiler, J. R., and B. Samuels, 1998: On the ocean's large-scale circulation near the limit of no vertical mixing. Journal of Physical Oceanography, 28 (9), 1832-1852.

Vallis, G. K., 2017: Atmospheric and oceanic fluid dynamics. Cambridge University Press.

Von Storch, H., and F. W. Zwiers, 2001: Statistical analysis in climate research. Cambridge university press. 
Winters, K. B., P. N. Lombard, J. J. Riley, and E. A. D’Asaro, 1995: Available potential energy and mixing in density-stratified fluids. Journal of Fluid Mechanics, 289, 115-128.

Winton, M., 1997: The damping effect of bottom topography on internal decadal-scale oscillations of the thermohaline circulation. Journal of physical oceanography, 27 (1), 203-208.

Zemskova, V. E., B. L. White, and A. Scotti, 2015: Available potential energy and the general circulation: Partitioning wind, buoyancy forcing, and diapycnal mixing. Journal of Physical Oceanography, 45 (6), 1510-1531.

Zemskova, V. E., B. L. White, and A. Scotti, 2021: Energetics of a rotating wind-forced horizontal convection model of a reentrant channel. Journal of Physical Oceanography, 51 (7), 2271-2290.

Zhang, R., R. Sutton, G. Danabasoglu, T. L. Delworth, W. M. Kim, J. Robson, and S. G. Yeager, 2016: Comment on “The Atlantic Multidecadal Oscillation without a role for ocean circulation". Science, 352 (6293), 1527-1527.

Zhang, R., R. Sutton, G. Danabasoglu, Y.-O. Kwon, R. Marsh, S. G. Yeager, D. E. Amrhein, and C. M. Little, 2019: A review of the role of the Atlantic Meridional Overturning Circulation in Atlantic multidecadal variability and associated climate impacts. Reviews of Geophysics, $\mathbf{5 7}$ (2), $316-375$. 
LIST OF TABLES

793 Table 1. List of all terms in the energy budget shown in figure 3

794 Table 2. Transfer values for all terms in the energy budget for the no wind $\left(\tau_{0}=\right.$ 


\begin{tabular}{|c|c|}
\hline \multicolumn{2}{|r|}{ KE and APE Dissipation } \\
\hline$D_{K E^{L F}}$ & $\rho_{0} \int_{V} \overline{\left(u^{L F} V_{u}^{L F}+v^{L F} V_{v}^{L F}\right)} \mathrm{d} V$ \\
\hline$D_{K E^{M E A N}}$ & $\rho_{0} \int_{V}\left(\bar{u} \overline{V_{u}}+\bar{v} \overline{V_{v}}\right) \mathrm{d} V$ \\
\hline$D_{K E^{H F}}$ & $-F_{K E^{M E A N}}-C(A P E, K E)-D_{K E^{L F}}-D_{K E^{M E A N}}$ \\
\hline$D_{A P E^{L F}}$ & $-\int_{V} g \overline{z_{r}(\rho, t) D^{L F}} \mathrm{~d} V$ \\
\hline$D_{A P E^{M E A N}}$ & $\int_{V} g z \bar{D} \mathrm{~d} V-\int_{V} g \overline{z_{r}(\rho, t)} \bar{D} \mathrm{~d} V$ \\
\hline$D_{A P E^{H F}}$ & $-F_{A P E^{M E A N}}-D_{A P E^{L F}}-D_{A P E^{M E A N}}+C(A P E, K E)$ \\
\hline \multicolumn{2}{|r|}{ KE and APE Forcing } \\
\hline$F_{K E^{M E A N}}$ & $\rho_{0} \int_{V} \bar{u} \overline{F_{u}} \mathrm{~d} V$ \\
\hline$F_{A P E^{M E A N}}$ & $-\int_{V} g \overline{z_{r}(\rho)} \bar{F} \mathrm{~d} V$ \\
\hline \multicolumn{2}{|r|}{ Conversion between reservoirs } \\
\hline$C\left(K E^{L F}, K E^{H F}\right)$ & $C\left(A P E^{L F}, K E^{L F}\right)+C\left(K E^{M E A N}, K E^{L F}\right)+D_{K E^{L F}}$ \\
\hline$C\left(K E^{M E A N}, K E^{L F}\right)$ & $\rho_{0} \int_{V}\left(\bar{u} \nabla \cdot \overline{\left(\mathbf{v}^{\mathbf{L F}} u^{L F}\right)}+\bar{v} \nabla \cdot \overline{\left(\mathbf{v}^{\mathbf{L F}} v^{L F}\right)}\right) \mathrm{d} V$ \\
\hline$C\left(K E^{M E A N}, K E^{H F}\right)$ & $F_{K E^{M E A N}}+C\left(A P E^{M E A N}, K E^{M E A N}\right)+D_{K E^{M E A N}}-C\left(K E^{M E A N}, K E^{L F}\right)$ \\
\hline$C\left(A P E^{L F}, A P E^{H F}\right)$ & $-C\left(A P E^{L F}, K E^{L F}\right)+C\left(A P E^{M E A N}, A P E^{L F}\right)+D_{A P E^{L F}}$ \\
\hline$C\left(A P E^{M E A N}, A P E^{L F}\right)$ & $-\int_{V} g \overline{\rho^{L F} w^{L F}} \mathrm{~d} V-g \int_{V} \overline{z_{r}(\rho, t) \mathbf{v}^{L F} \cdot \nabla \rho^{L F}}-\overline{z_{r}(\rho, t) \overline{\mathbf{v}} \cdot \nabla \rho^{L F}} \mathrm{~d} V$ \\
\hline$C\left(A P E^{M E A N}, A P E^{H F}\right)$ & $-C\left(A P E^{M E A N}, A P E^{L F}\right)-C\left(A P E^{M E A N}, K E^{M E A N}\right)+D_{A P E^{M E A N}}+F_{A P E^{M E A N}}$ \\
\hline$C\left(A P E^{M E A N}, K E^{M E A N}\right)$ & $-\int_{V} g \bar{\rho} \bar{w} \mathrm{~d} V$ \\
\hline$C\left(A P E^{L F}, K E^{L F}\right)$ & $-\int_{V} g \overline{\rho^{L F} w_{w^{L F}} \mathrm{~d} V}$ \\
\hline$C\left(A P E^{H F}, K E^{H F}\right)$ & $C(A P E, K E)-C\left(A P E^{M E A N}, K E^{L F}\right)-C\left(A P E^{M E A N}, K E^{M E A N}\right)$ \\
\hline$C(A P E, K E)$ & $\int_{V} g z \overline{\nabla \mathbf{v} \rho} \mathrm{d} V$ \\
\hline
\end{tabular}

TABLE 1. List of all terms in the energy budget shown in figure 3 


\begin{tabular}{|c|c|c|c|}
\hline & $\tau_{0}=0 \mathrm{Nm}^{-2}$ & $\tau_{0}=0.05 \mathrm{Nm}^{-2}$ & $\tau_{0}=0.1 \mathrm{Nm}^{-2}$ \\
\hline \multicolumn{4}{|c|}{ KE and APE Dissipation } \\
\hline$D_{K E^{L F}}$ & $-5 \mathrm{GW}$ & $-3 \mathrm{GW}$ & $-2 \mathrm{GW}$ \\
\hline$D_{K E^{M E A N}}$ & $-5 \mathrm{GW}$ & $-8 \mathrm{GW}$ & $-15 \mathrm{GW}$ \\
\hline$D_{K E^{H F}}$ & $-22 \mathrm{GW}$ & $-22 \mathrm{GW}$ & $-36 \mathrm{GW}$ \\
\hline$D_{A P E^{L F}}$ & $-16 \mathrm{GW}$ & $-7 \mathrm{GW}$ & $-5 \mathrm{GW}$ \\
\hline$D_{A P E^{M E A N}}$ & $-18 \mathrm{GW}$ & $-30 \mathrm{GW}$ & $-42 \mathrm{GW}$ \\
\hline$D_{A P E^{H F}}$ & $-53 \mathrm{GW}$ & $-56 \mathrm{GW}$ & $-62 \mathrm{GW}$ \\
\hline \multicolumn{4}{|c|}{ KE and APE Forcing } \\
\hline$F_{K E^{M E A N}}$ & $0 \mathrm{GW}$ & $7 \mathrm{GW}$ & $34 \mathrm{GW}$ \\
\hline$F_{A P E^{M E A N}}$ & $119 \mathrm{GW}$ & $119 \mathrm{GW}$ & $128 \mathrm{GW}$ \\
\hline \multicolumn{4}{|c|}{ Conversion between reservoirs } \\
\hline$C\left(K E^{L F}, K E^{H F}\right)$ & $0 \mathrm{GW}$ & $0 \mathrm{GW}$ & $-1 \mathrm{GW}$ \\
\hline$C\left(K E^{M E A N}, K E^{L F}\right)$ & $1 \mathrm{GW}$ & $1 \mathrm{GW}$ & $0 \mathrm{GW}$ \\
\hline$C\left(K E^{M E A N}, K E^{H F}\right)$ & $2 \mathrm{GW}$ & $3 \mathrm{GW}$ & $8 \mathrm{GW}$ \\
\hline$C\left(A P E^{L F}, A P E^{H F}\right)$ & $29 \mathrm{GW}$ & $14 \mathrm{GW}$ & $7 \mathrm{GW}$ \\
\hline$C\left(A P E^{M E A N}, A P E^{L F}\right)$ & $49 \mathrm{GW}$ & $23 \mathrm{GW}$ & $13 \mathrm{GW}$ \\
\hline$C\left(A P E^{M E A N}, A P E^{H F}\right)$ & $44 \mathrm{GW}$ & $61 \mathrm{GW}$ & $84 \mathrm{GW}$ \\
\hline$C\left(A P E^{M E A N}, K E^{M E A N}\right)$ & $8 \mathrm{GW}$ & $5 \mathrm{GW}$ & $-11 \mathrm{GW}$ \\
\hline$C\left(A P E^{L F}, K E^{L F}\right)$ & $4 \mathrm{GW}$ & $2 \mathrm{GW}$ & $1 \mathrm{GW}$ \\
\hline$C\left(A P E^{H F}, K E^{H F}\right)$ & $20 \mathrm{GW}$ & $19 \mathrm{GW}$ & $29 \mathrm{GW}$ \\
\hline$C(A P E, K E)$ & $32 \mathrm{GW}$ & $26 \mathrm{GW}$ & $19 \mathrm{GW}$ \\
\hline
\end{tabular}

TABLE 2. Transfer values for all terms in the energy budget for the no wind $\left(\tau_{0}=0 \mathrm{Nm}^{-2}\right)$, intermediate wind

$\tau_{0}=\left(0.05 \mathrm{Nm}^{-2}\right)$ and climatological wind $\left(\tau_{0}=0.1 \mathrm{Nm}^{-2}\right)$ experiments 


\section{LIST OF FIGURES}

Fig. 1. Schematic showing how the reference depth $z_{r}$ associated with a given density $\rho$ is calculated. Left: meridional section of the physical space where volume $V_{1}$ (coloured in red) above the isopycnal $\rho=$ const. is shown. Right: adiabatic rearrangement where the previous isopycnal is horizontal with the same volume of water $V_{1}$ above it. $z_{r}(\rho)$ is the depth of this isopycnal after the rearrangement.

Fig. 2. Time evolution (in years) of the reference depth (in $\mathrm{m}$ ) of several isotherms $\left(\right.$ in ${ }^{\circ} \mathrm{C}$ ) in the experiment without wind forcing.

Fig. 3. Schematic view of the transfer between the different reservoirs of LF, HF and mean APE and $\mathrm{KE}$, and BPE. KE dissipation is in blue, KE forcing is in red, transfers between reservoirs are in orange, BPE/APE transfer due to forcing and parametrized diffusion are in pink and green, respectively. Names of all transfers are indicated near the corresponding arrow and summarized in table (1).

Fig. 4. Analytical zonal wind stress as a function of latitude for $\tau_{0}=0 \mathrm{Nm}^{-2}$ (blue line), $\tau_{0}=0.05 \mathrm{Nm}^{-2}$ (orange line) and $\tau_{0}=0.1 \mathrm{Nm}^{-2}$ (green line).

Fig. 5. Volume average of the temperature spectrum as a function of frequency calculated from 5 days (orange line) and 50 days (blue line) average outputs for $\tau_{0}=0 \mathrm{~N} \mathrm{~m}^{-2}$ (top left panel), $0.05 \mathrm{~N} \mathrm{~m}^{-2}$ (top right panel) and $0.1 \mathrm{Nm}^{-2}$ (bottom panel). The black vertical lines on each panel show the peak magnitude for each experiment and the red vertical lines show the LF/HF 3.5 year separation.

Fig. 6. First Complex EOF calculated on 1 year averaged 3D temperature outputs $\left({ }^{\circ} \mathrm{C}\right)$ of the $\tau_{0}=$ $0 \mathrm{~N} \mathrm{~m}^{-2}$ run, accounting for $60 \%$ of the variability. Top left: real part of the SST, top right imaginary part of the SST. Middle left: CEOF real part along the meridional section (longitude $=800 \mathrm{~km}$ ) shown by a red line on the top left and right panels, middle right: imaginary part along the same section. Black contours show isotherms of the time mean temperature. Bottom: real (red solid) and imaginary (red dotted) part of the principal component of the first CEOF. The blue line shows the time evolution of the APE (in EJ).

Fig. 7. Left column: Sea Surface height standard deviation (m) calculated from 50 days average and time mean (black contours), middle column: vertical integral of the time mean LF density variance $\left(\mathrm{kg}^{2} \mathrm{~m}^{-5}\right)$, right column: time mean of the vertical integral of the LF APE $\left(\mathrm{J} \mathrm{m}^{-2}\right)$. $\tau_{0}=0 \mathrm{Nm}^{-2}, 0.05 \mathrm{Nm}^{-2}$ and $0.1 \mathrm{Nm}^{-2}$ are respectively shown on the first, second and third line. Note that the colorscale is different for each figure.

Fig. 8. Same as in Figure 6 but for an intermediate double gyre wind forcing of $\tau_{0}=0.05 \mathrm{Nm}^{-2}$. The leading CEOF accounts for $28 \%$ of the temperature variance. The red line on the two top figures shows the same meridional section as in Fig. 6 used to plot the two figures in the middle.

Fig. 9. Same as in Figure 6 but for a climatological double gyre wind forcing of $\tau_{0}=0.1 \mathrm{Nm}^{-2}$. The leading CEOF accounts for $7 \%$ of the temperature variance.

Fig. 10. Schematic showing the Exchange of Energy between the different reservoirs (shown by black boxes) for the $\tau_{0}=0 \mathrm{Nm}^{-2}$ run. The conversion from BPE to APE forcing achieved by surface heat fluxes is shown by green arrows, the conversion of APE to BPE because of diffusive fluxes are shown in pink. Dissipation of KE by viscous forces is shown by blue arrows and the conversion between the different reservoirs by orange arrows. The direction 
of the conversion follows the arrow direction. Conversions are expressed in $\mathrm{GW}=10^{9} \mathrm{~W}$, the $\mathrm{KE}$ in $\mathrm{PJ}=10^{15} \mathrm{~J}$ and the APE in $\mathrm{EJ}=10^{18} \mathrm{~J}$.

Fig. 11. Vertical integral of the conversion between mean APE and HF APE (first column) $C\left(A P E^{M E A N}, A P E^{H F}\right)$, mean APE and LF APE $C\left(A P E^{M E A N}, A P E^{L F}\right)$ (second column). Unit is in GW. The third column shows the vertical integral of the density variance transfer from mean to LF (units: $\mathrm{kg}^{2} \mathrm{~m}^{-6} \mathrm{~s}^{-1}$ ). Note that the colorbar differs between the different rows. The last column shows the mean APE forcing (or transfer from BPE to mean APE due to heat fluxes) (unit GW). The first, second, and third line show respectively the three conversion term for the three wind intensity $\tau_{0}=0 \mathrm{~N} / \mathrm{m}^{2}, \tau_{0}=0.05 \mathrm{~N} / \mathrm{m}^{2}$ and $\tau_{0}=0.1$ $N / m^{2} . C\left(A P E^{L F}, A P E^{H F}\right)$ is not shown but look very similar to $C\left(A P E^{M E A N}, A P E^{L F}\right)$. . . . 56

Fig. 12. Same as figure 10 but with an intermediate double gyre wind stress surface forcing of $\tau_{0}=$ $0.05 \mathrm{Nm}^{-2}$. The KE forcing made by the wind stress is shown with a red arrow.

Fig. 13. Same as figure 10 but with a double gyre wind stress surface forcing of $\tau_{0}=0.1 \mathrm{Nm}^{-2}$. The $\mathrm{KE}$ forcing made by the wind stress is shown with a red arrow. 
Physical Space

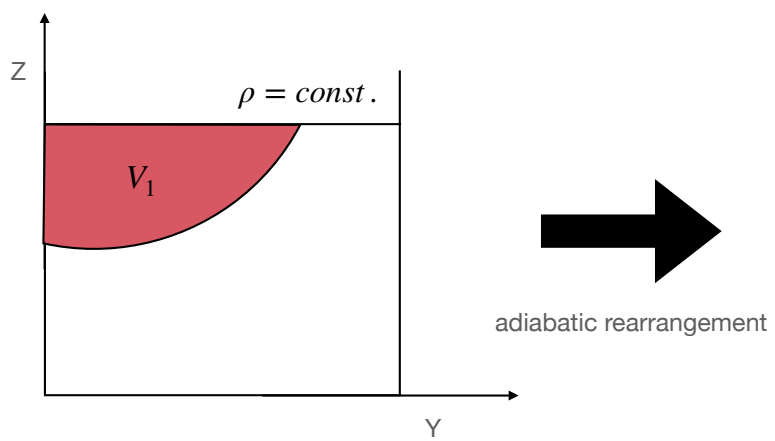

Reference Space

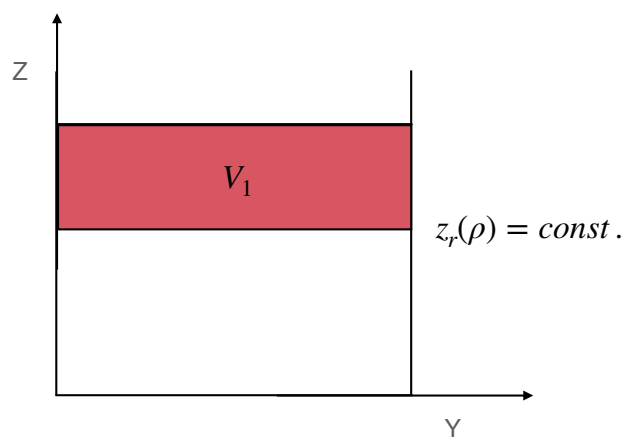

FIG. 1. Schematic showing how the reference depth $z_{r}$ associated with a given density $\rho$ is calculated. Left: meridional section of the physical space where volume $V_{1}$ (coloured in red) above the isopycnal $\rho=$ const . is shown. Right: adiabatic rearrangement where the previous isopycnal is horizontal with the same volume of water $V_{1}$ above it. $z_{r}(\rho)$ is the depth of this isopycnal after the rearrangement. 


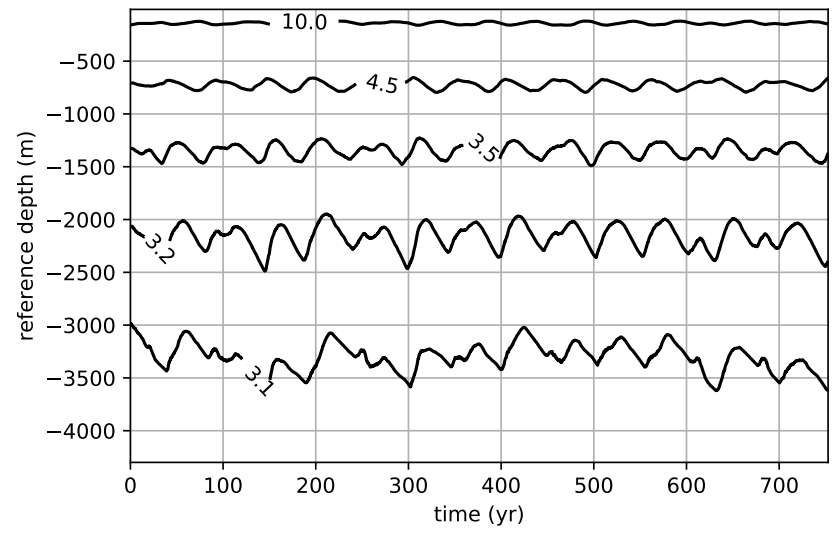
without wind forcing. 


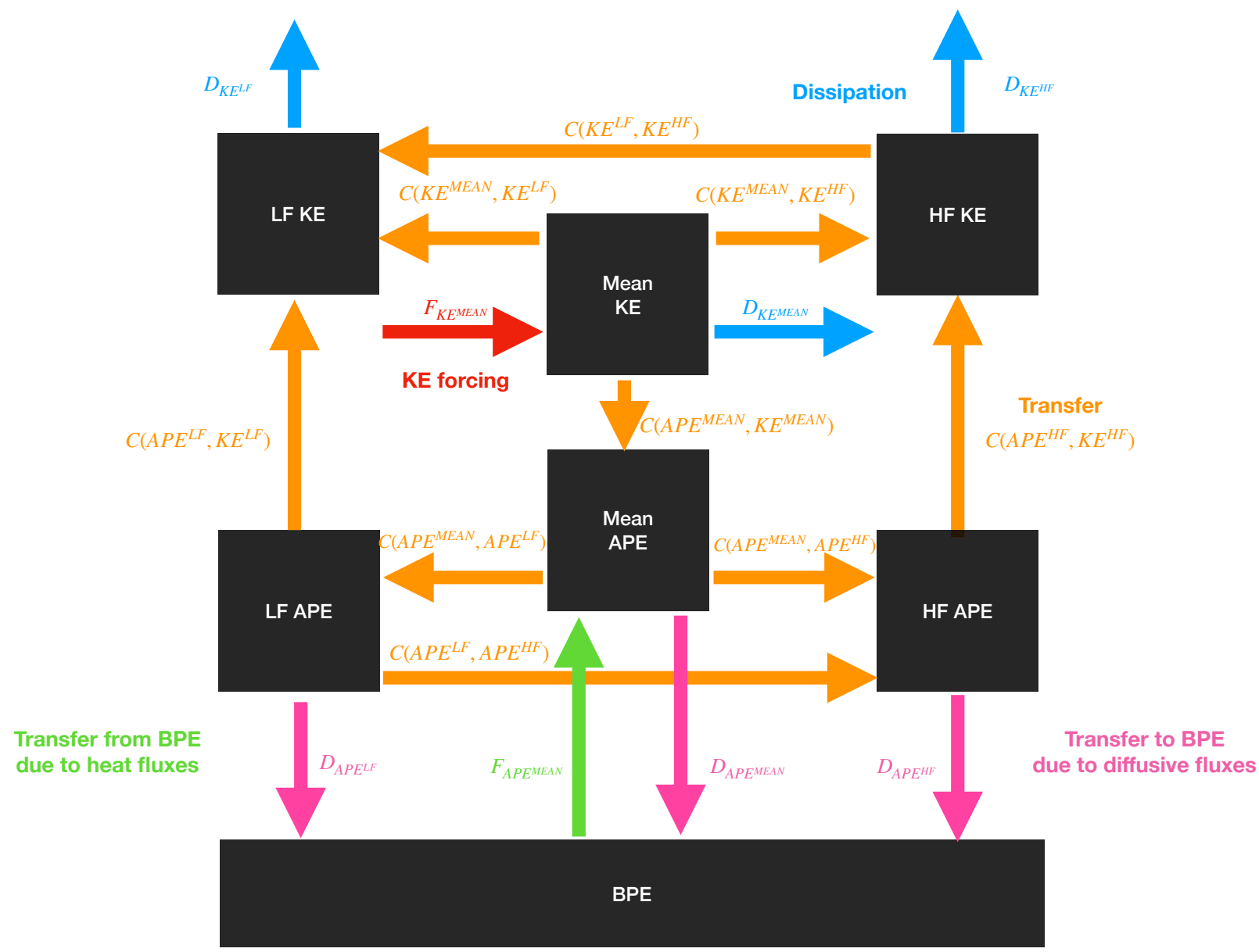

FIG. 3. Schematic view of the transfer between the different reservoirs of LF, HF and mean APE and KE, and BPE. KE dissipation is in blue, KE forcing is in red, transfers between reservoirs are in orange, BPE/APE transfer due to forcing and parametrized diffusion are in pink and green, respectively. Names of all transfers are indicated near the corresponding arrow and summarized in table (1). 


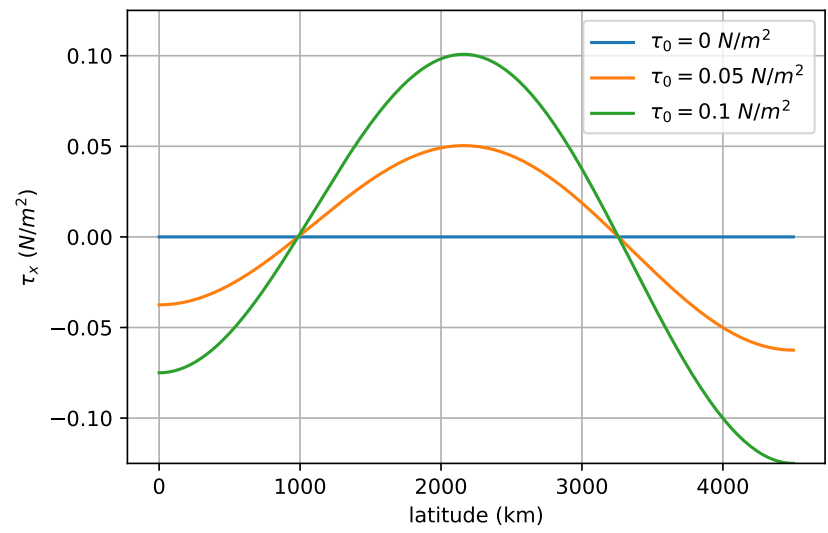

FIG. 4. Analytical zonal wind stress as a function of latitude for $\tau_{0}=0 \mathrm{Nm}^{-2}$ (blue line), $\tau_{0}=0.05 \mathrm{Nm}^{-2}$ ${ }_{867}$ (orange line) and $\tau_{0}=0.1 \mathrm{Nm}^{-2}$ (green line). 


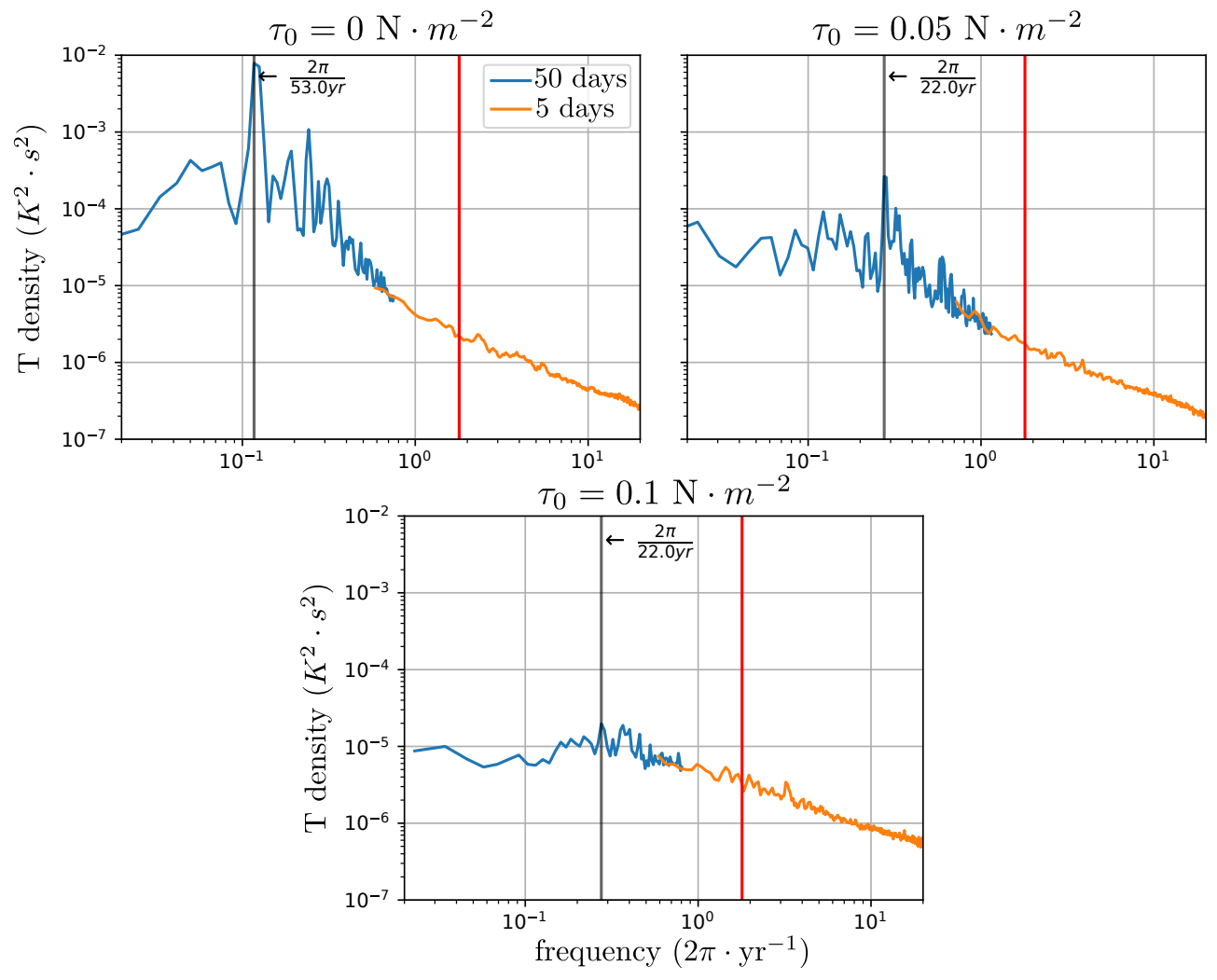

FIG. 5. Volume average of the temperature spectrum as a function of frequency calculated from 5 days (orange

line) and 50 days (blue line) average outputs for $\tau_{0}=0 \mathrm{Nm}^{-2}$ (top left panel), $0.05 \mathrm{Nm}^{-2}$ (top right panel) and $0.1 \mathrm{~N} \mathrm{~m}^{-2}$ (bottom panel). The black vertical lines on each panel show the peak magnitude for each experiment and the red vertical lines show the LF/HF 3.5 year separation. 

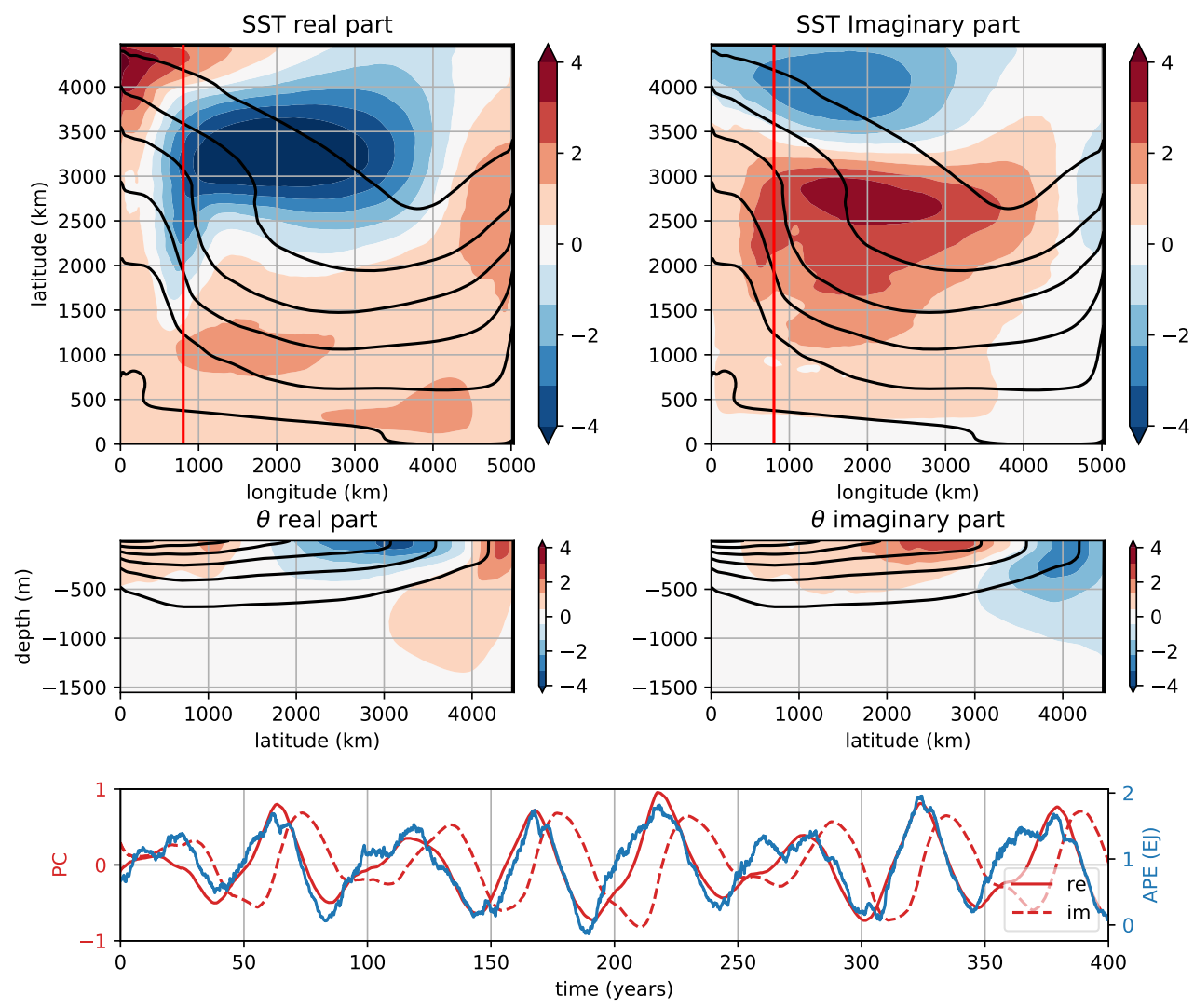

FIG. 6. First Complex EOF calculated on 1 year averaged 3D temperature outputs $\left({ }^{\circ} \mathrm{C}\right)$ of the $\tau_{0}=0 \mathrm{Nm}^{-2}$

run, accounting for $60 \%$ of the variability. Top left: real part of the SST, top right imaginary part of the SST.

Middle left: $\mathrm{CEOF}$ real part along the meridional section (longitude $=800 \mathrm{~km}$ ) shown by a red line on the top left and right panels, middle right: imaginary part along the same section. Black contours show isotherms of the time mean temperature. Bottom: real (red solid) and imaginary (red dotted) part of the principal component of the first CEOF. The blue line shows the time evolution of the APE (in EJ). 

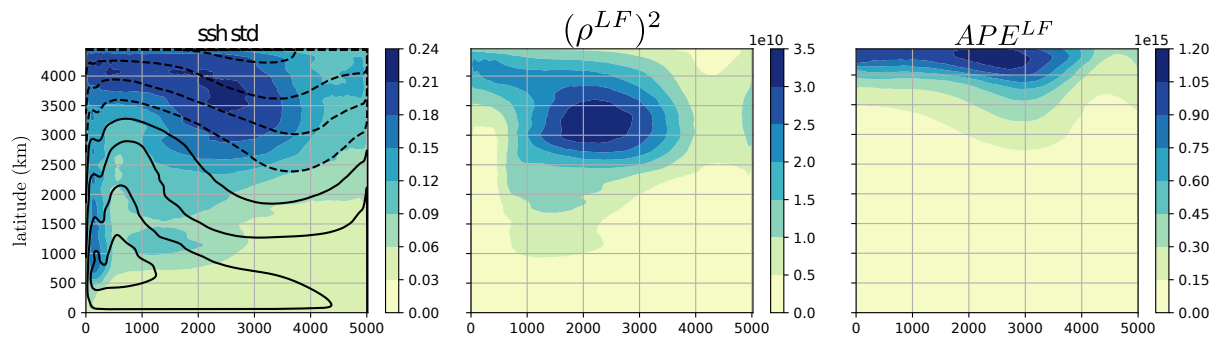

$\tau_{0}=0 \mathrm{~N} / \mathrm{m}^{2}$
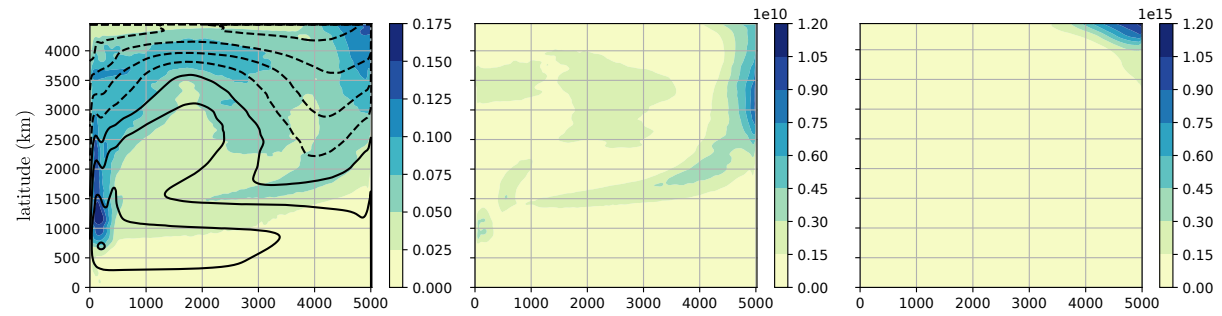

$\tau_{0}=0.05 \mathrm{~N} / \mathrm{m}^{2}$
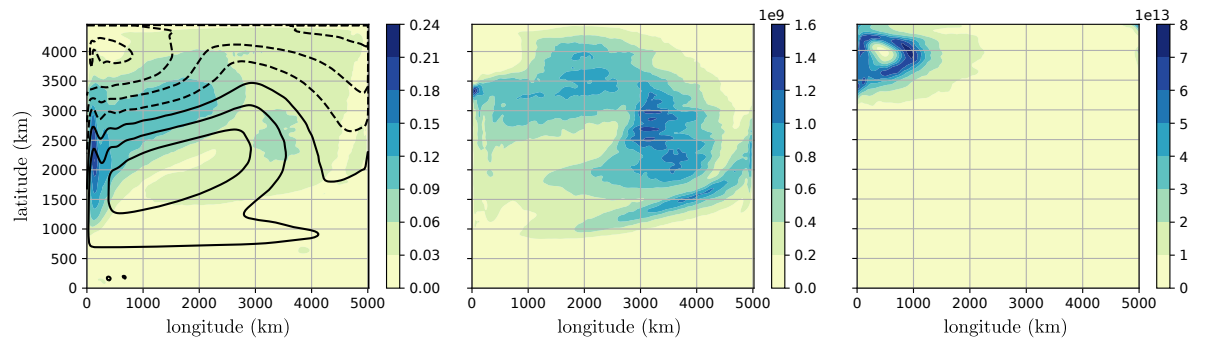

$\tau_{0}=0.1 \mathrm{~N} / \mathrm{m}^{2}$

FIG. 7. Left column: Sea Surface height standard deviation $(\mathrm{m})$ calculated from 50 days average and time mean (black contours), middle column: vertical integral of the time mean LF density variance $\left(\mathrm{kg}^{2} \mathrm{~m}^{-5}\right)$, right column: time mean of the vertical integral of the LF APE $\left(\mathrm{Jm}^{-2}\right) \cdot \tau_{0}=0 \mathrm{Nm}^{-2}, 0.05 \mathrm{Nm}^{-2}$ and $0.1 \mathrm{Nm}^{-2}$ are respectively shown on the first, second and third line. Note that the colorscale is different for each figure. 

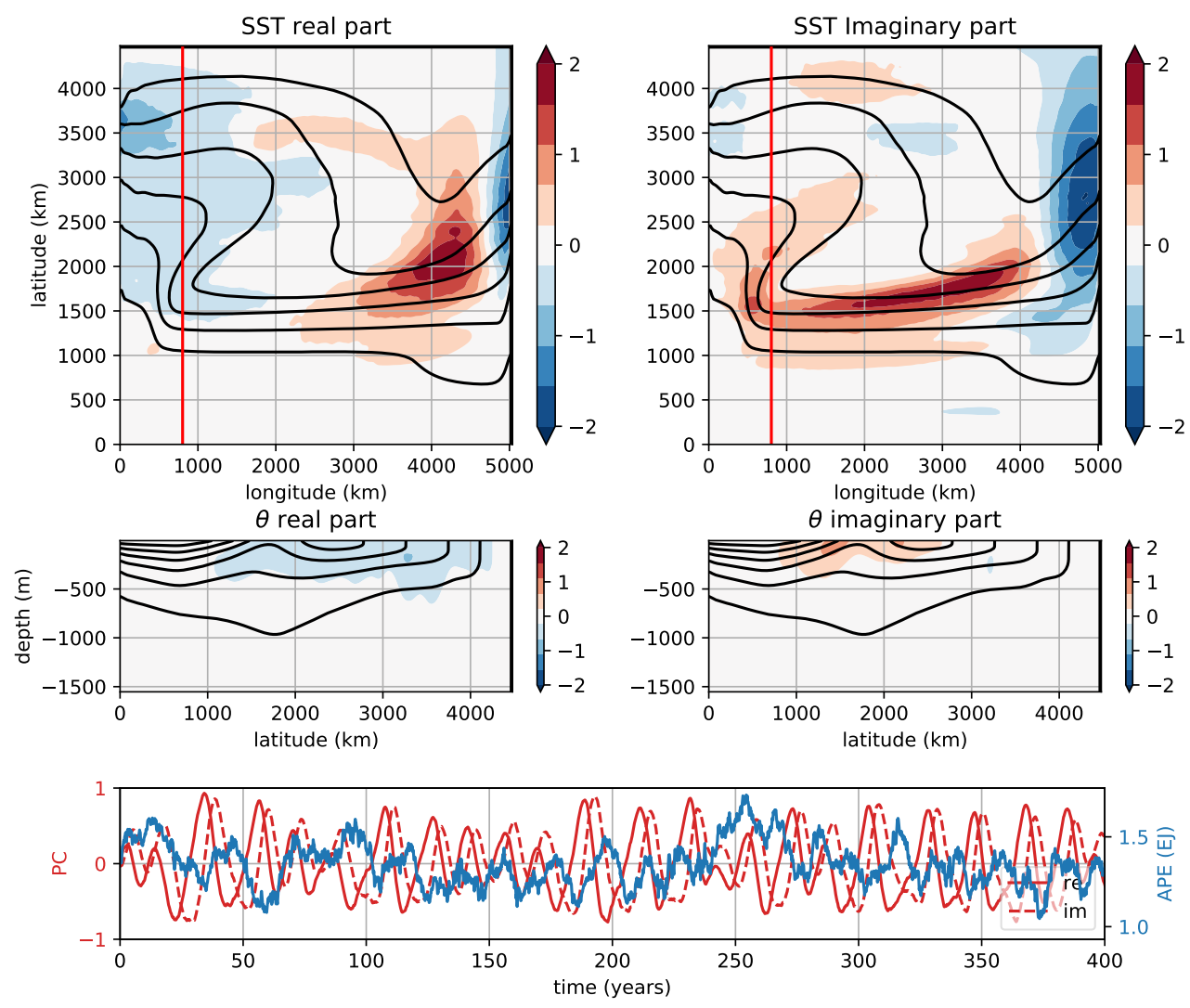

FIG. 8. Same as in Figure 6 but for an intermediate double gyre wind forcing of $\tau_{0}=0.05 \mathrm{Nm}^{-2}$. The leading CEOF accounts for $28 \%$ of the temperature variance. The red line on the two top figures shows the same meridional section as in Fig. 6 used to plot the two figures in the middle. 

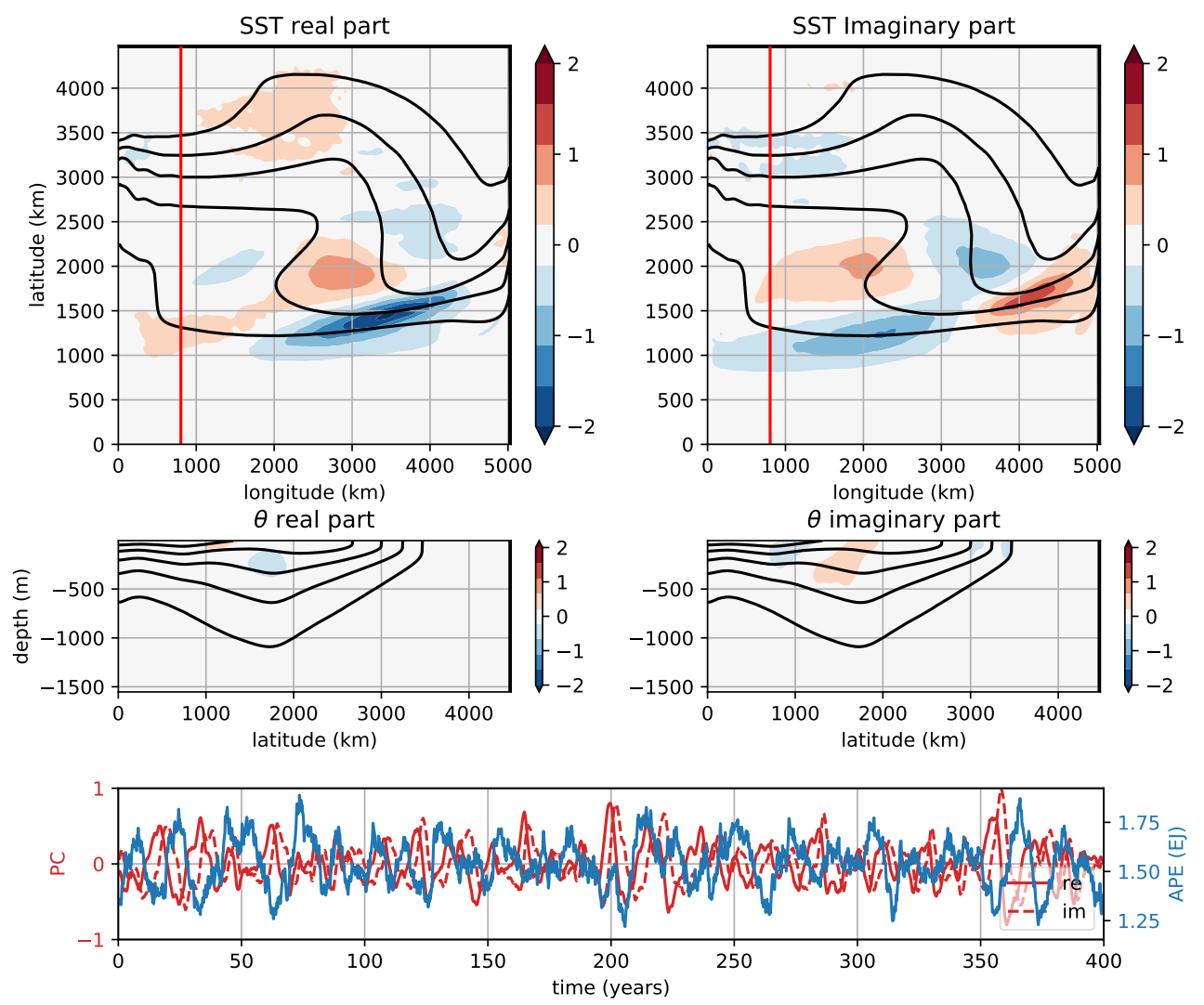

FIG. 9. Same as in Figure 6 but for a climatological double gyre wind forcing of $\tau_{0}=0.1 \mathrm{Nm}^{-2}$. The leading

CEOF accounts for $7 \%$ of the temperature variance. 


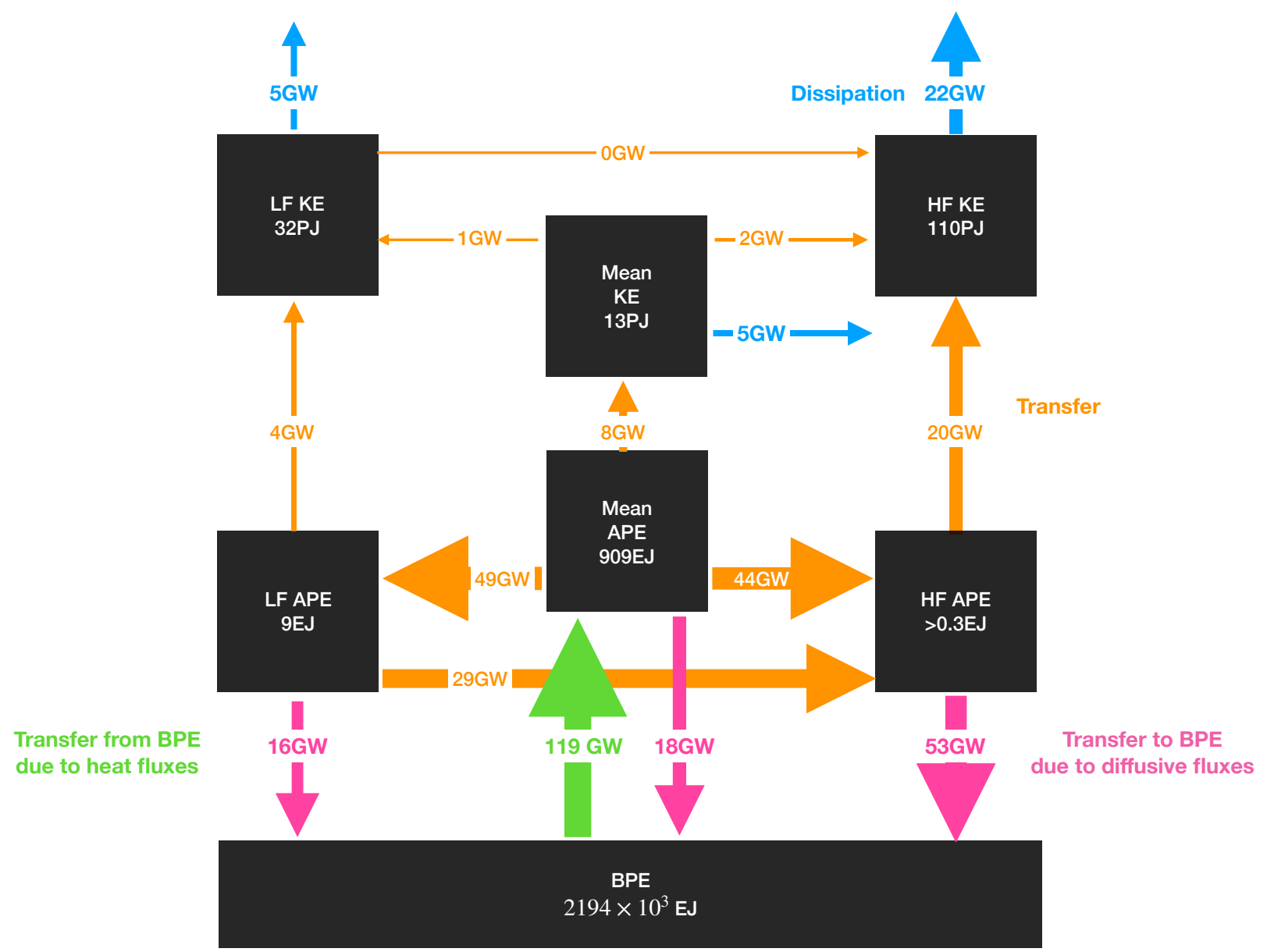

FIG. 10. Schematic showing the Exchange of Energy between the different reservoirs (shown by black boxes) for the $\tau_{0}=0 \mathrm{~N} \mathrm{~m}^{-2}$ run. The conversion from BPE to APE forcing achieved by surface heat fluxes is shown by green arrows, the conversion of APE to BPE because of diffusive fluxes are shown in pink. Dissipation of KE by viscous forces is shown by blue arrows and the conversion between the different reservoirs by orange arrows.

The direction of the conversion follows the arrow direction. Conversions are expressed in $\mathrm{GW}=10^{9} \mathrm{~W}$, the $\mathrm{KE}$ in $\mathrm{PJ}=10^{15} \mathrm{~J}$ and the $\mathrm{APE}$ in $\mathrm{EJ}=10^{18} \mathrm{~J}$. 

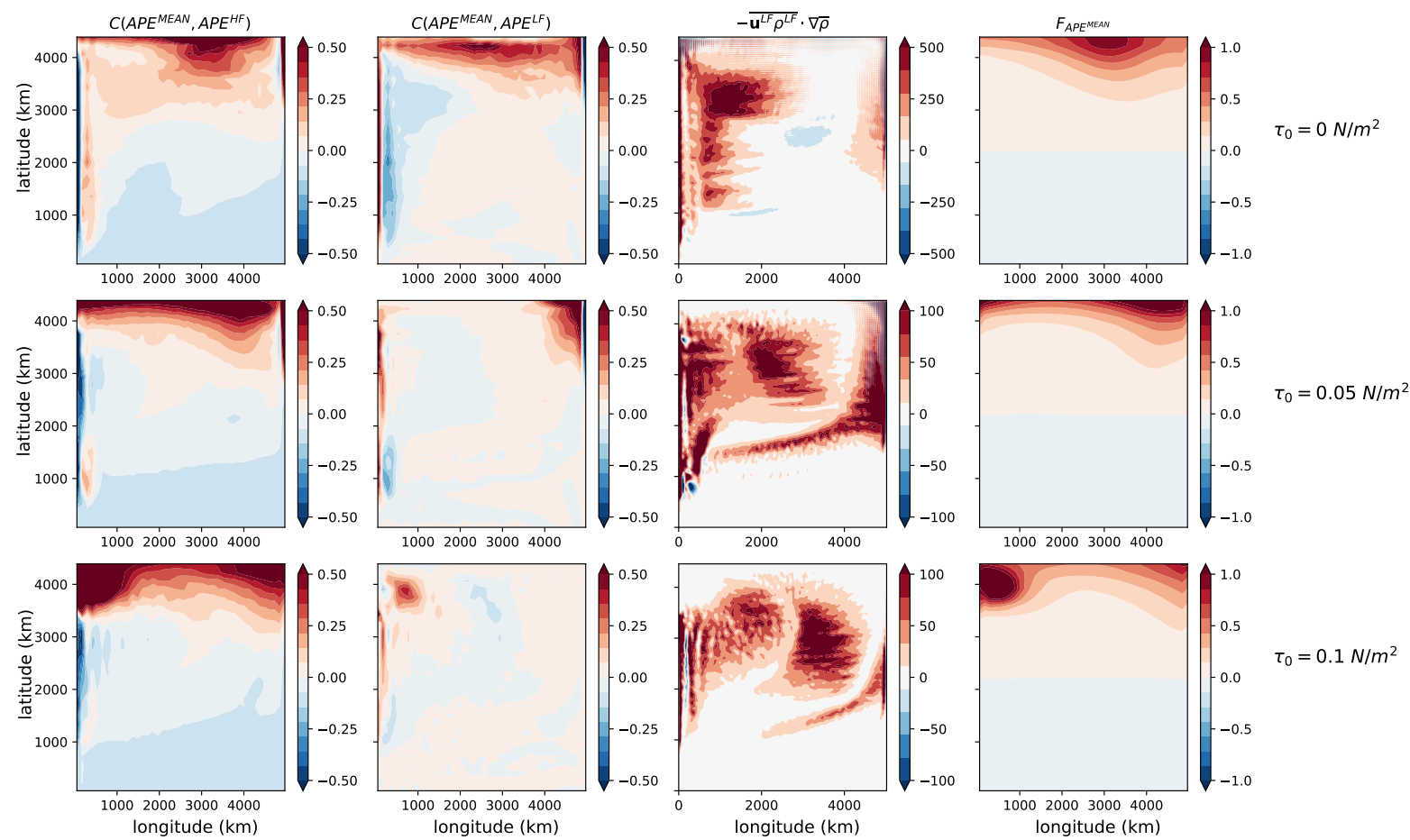

FIG. 11. Vertical integral of the conversion between mean APE and HF APE (first column) $C\left(A P E^{M E A N}, A P E^{H F}\right)$, mean APE and LF APE $C\left(A P E^{M E A N}, A P E^{L F}\right)$ (second column). Unit is in GW. The third column shows the vertical integral of the density variance transfer from mean to LF (units: $\mathrm{kg}^{2} \mathrm{~m}^{-6} \mathrm{~s}^{-1}$ ). Note that the colorbar differs between the different rows. The last column shows the mean APE forcing (or transfer from BPE to mean APE due to heat fluxes) (unit GW). The first, second, and third line show respectively the three conversion term for the three wind intensity $\tau_{0}=0 \mathrm{~N} / \mathrm{m}^{2}, \tau_{0}=0.05 \mathrm{~N} / \mathrm{m}^{2}$ and $\tau_{0}=0.1 \mathrm{~N} / \mathrm{m}^{2}$. $C\left(A P E^{L F}, A P E^{H F}\right)$ is not shown but look very similar to $C\left(A P E^{M E A N}, A P E^{L F}\right)$. 


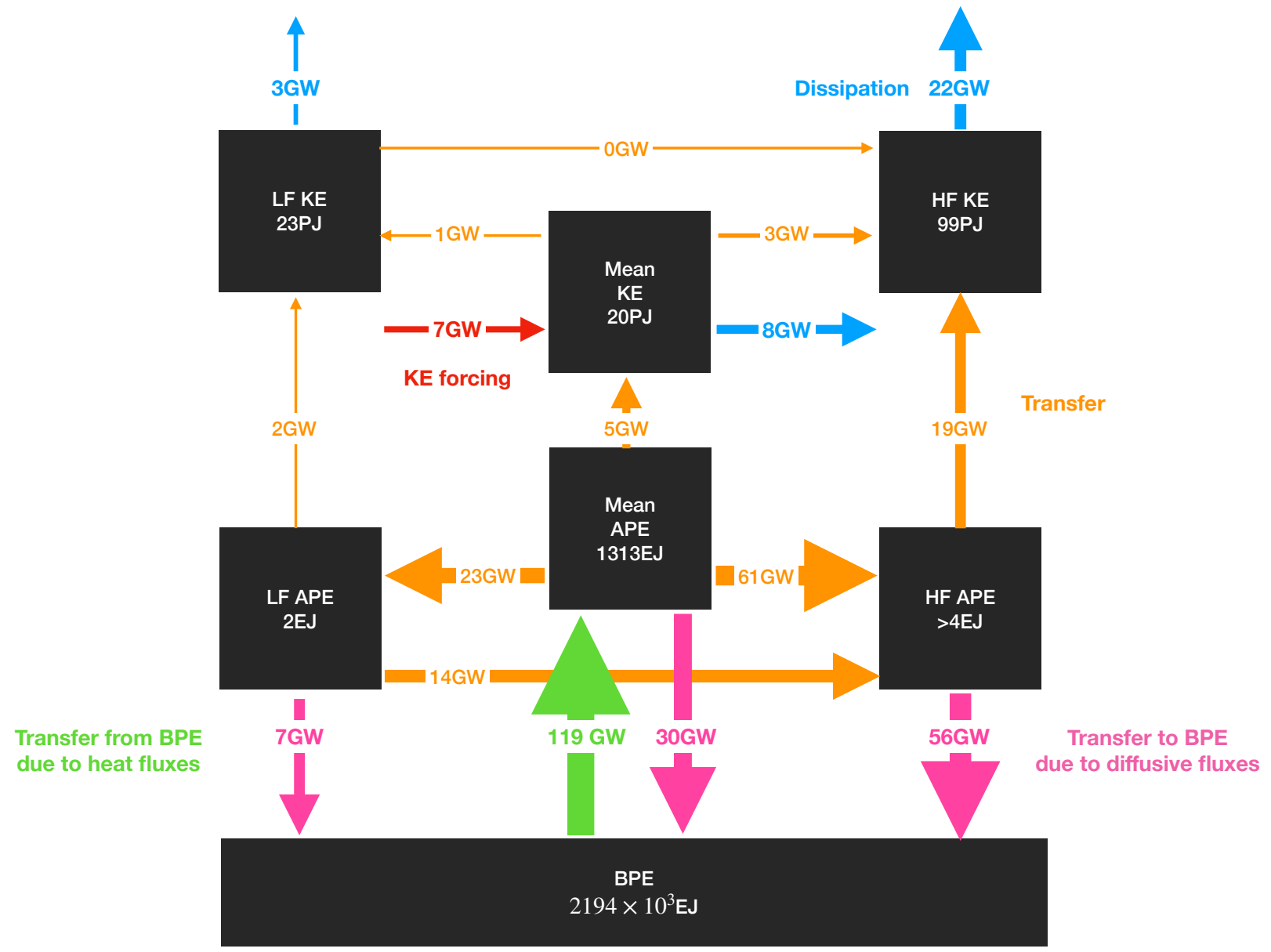

FIG. 12. Same as figure 10 but with an intermediate double gyre wind stress surface forcing of $\tau_{0}=$ ${ }_{901} 0.05 \mathrm{~N} \mathrm{~m}^{-2}$. The KE forcing made by the wind stress is shown with a red arrow. 


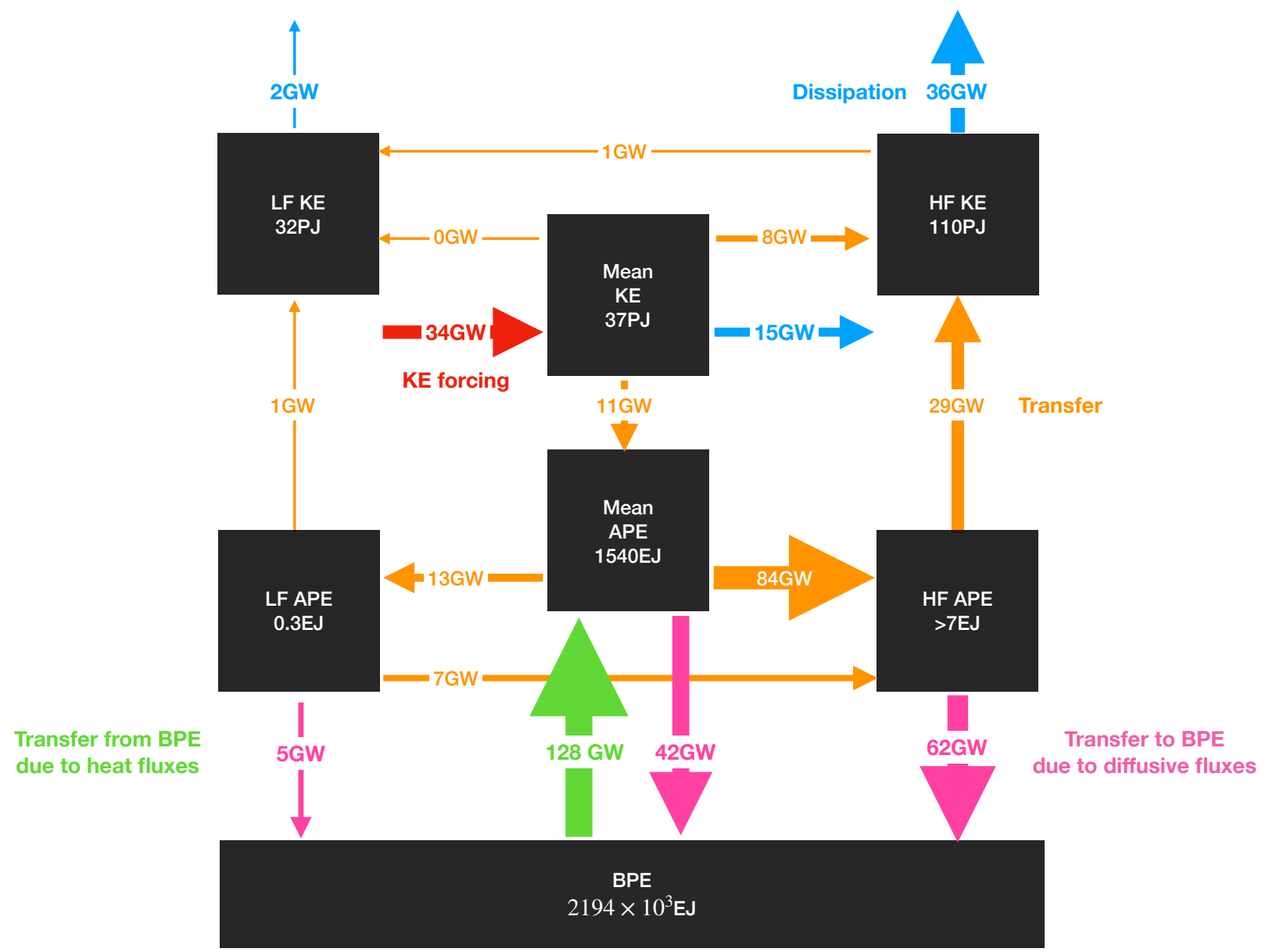

FIG. 13. Same as figure 10 but with a double gyre wind stress surface forcing of $\tau_{0}=0.1 \mathrm{Nm}^{-2}$. The KE forcing made by the wind stress is shown with a red arrow. 